\title{
Bioanalysis
}

\section{Development and characterization of a pseudo multiple reaction monitoring method for the quantification of human uromodulin in urine}

Background: Uromodulin is the most abundant protein in healthy human urine. Recently it has been suggested as a specific biomarker of renal tubular damage. We have developed a novel pseudo multiple reaction monitoring (pseudo MRM) for the protein's quantification in human urine. Results: Selection of two peptides allowed quantification of uromodulin in human urine. The pseudo MRM quantified uromodulin in healthy individuals between 21 and $1344 \mathrm{nM}$ and in autosomal dominant tubulointerstitial kidney disease-UMOD patients between 2 and $25 \mathrm{nM}$. Conclusion: The pseudo MRM allows greater confidence in assay specificity than traditional MRM methods and quantified uromodulin at concentrations higher than achievable by ELISA. Differences in urinary uromodulin concentration related to the rs4293393 promoter variant in the UMOD gene was confirmed. This method will be used to further investigate uromodulin as a biomarker of renal injury.

First draft submitted: 8 March 2016; Accepted for publication: 27 April 2016;

Published online: 17 May 2016

Keywords: autosomal-dominant tubulointerstitial kidney disease-UMOD • biomarker - MS • multiple reaction monitoring $\bullet$ protein quantification $\bullet$ pseudo multiple reaction monitoring • selected reaction monitoring • Tamm-Horsfall protein • thick ascending limb

Uromodulin (Tamm-Horsfall protein) is a protein that is exclusively synthesized by the renal tubular epithelial cells lining the thick ascending limb (TAL) of the loop of Henle [1]. After synthesis uromodulin is predominantly trafficked to the apical membrane, where it is cleaved, released into the urine and subsequently assembles into polymeric filaments. Uromodulin represents the most abundant protein in urine of healthy individuals, with an estimated production rate of 50-100 mg/day [2].

Although the first reports describing uromodulin were published in 1950 [3], its biological functions are still not fully understood. Studies using knockout mice have shown uromodulin to regulate $\mathrm{NaCl}$ reabsorption by the kidney tubule $[4,5]$, protect against urinary tract infection and prevent the formation of kidney stones [6]. Furthermore, mutations in the UMOD gene cause rare, autosomal dominant tubulointerstitial kidney disorders [7]. Uromodulin has also been suggested as a unique marker of renal tubular function. This is a consequence of its exclusive production in the TAL, which plays a major role in the handling of sodium and divalent cations, as well as in urinary concentrating ability. Supporting this hypothesis, recent population-based studies have demonstrated positive associations of urinary uromodulin concentration with urinary electrolytes, osmolality and kidney dimensions [8,9]. This indicates that uromodulin excretion could represent a useful marker of tubular function, and its potential utility in monitoring renal function in clinical practice.

In order to definitively ascertain uromodulin's functions in man, as well as to provide suitable assessment into its potential utility
Thomas G Hammond ${ }^{1,2}$, Suzette Moes ${ }^{3}$, Sonia Youhanna ${ }^{2,4}$, Paul Jennings ${ }^{5}$, Olivier Devuyst ${ }^{2,4}$, Alex Odermatt ${ }^{*, 1,2} \&$ Paul Jenö**,3 'Division of Molecular \& Systems Toxicology, Department of Pharmaceutical Sciences, University of Basel, Klingelbergstrasse 50-70, 4056, Basel, Switzerland

${ }^{2}$ Swiss National Centre of Competence in Research (NCCR) Kidney Control of Homeostasis

${ }^{3}$ Proteomics Core Facility, Biozentrum, University of Basel, Klingelbergstrasse 50-70, 4056, Basel, Switzerland ${ }^{4}$ Institute of Physiology, Zurich Centre for Integrative Human Physiology, University of Zurich, Zurich, Switzerland

${ }^{5}$ Division of Physiology, Department of Physiology \& Medical Physics, Medical University of Innsbruck, Innsbruck, Austria

*Author for correspondence:

Tel.: +41612671530

Fax: +41612671515

alex.odermatt@unibas.ch

**Author for correspondence:

Tel.: +41 612672156

paul.jenoe@unibas.ch 
to serve as a biomarker, accurate quantification of the protein in urine is required. Currently, uromodulin is almost exclusively measured by immunoassay, and predominantly quantified by ELISA. ELISAs however, may have potential liabilities affecting their accurate measurement of uromodulin. Approximately $38 \%$ of uromodulin's mass has been attributed to $\mathrm{N}$-glycosylation [10,11]. Eight sites of potential N-glycosylation have been identified, with seven of these experimentally verified (Figure 1) [12]. O-glycosylation of uromodulin has also been demonstrated [11,13], but this only accounts for a minor fraction of the protein's total glycosylation. These post-translational modifications of the protein may potentially mask sites of antibody binding. Additionally, the protein's propensity to form aggregates, particularly in high ionic strength buffers and matrices, as is found in urine, may also result in masking of antibody binding sites as well as leading to the precipitation of the protein. Consequently we have looked to develop a mass spectrometric-based method for the quantification of uromodulin in human urine.

Urine represents a challenging matrix for the quantitation of proteins using mass-spectrometry (MS). It contains a low total protein concentration, high amounts of salts and other potentially interfering components. Furthermore, samples often exhibit high inter- and intraindividual variability [14]. While mass-spectrometric quantification of proteins in urine have previously been reported, these methods generally required protein enrichment from large urinary volumes [15], fractionation [16] or protein precipitation and clean-up [17]. Furthermore they also generally utilize standard multiple reaction monitoring (MRM) methods on triple quadrupole mass spectrometers.

We have decided to investigate the utility of MS for the quantification of uromodulin in human urine. Utilizing an LTQ Orbitrap mass-spectrometer we have developed a simple pseudo multiple reaction monitor- ing method (pseudo MRM) to quantify uromodulin concentrations in human urine. Following detailed validation of the method and comparison with ELISA, urinary uromodulin concentration in a human cohort was assessed. This cohort exhibited a single nucleotide polymorphism in the UMOD promotor, namely the rs4293393 variant. This variant has two alleles: T, the reference allele, which has a population frequency in the European population of $80 \%$, and C, the rare allele (based on the reverse strand) [18]. In vitro experiments have revealed the homozygous rs4293393-T genotype (TT) to result in increased transcription of the UMOD gene in comparison to the homozygous rs4293393-C genotype (CC) [19]. This increased renal transcription in individuals exhibiting the TT genotype has been shown to result in greater urinary uromodulin concentration [19,20], alongside an increased risk for development of chronic kidney disease (CKD), salt-sensitive hypertension and gout, but a reduced risk of kidney stone formation $[18,19,21]$. Subsequently, we then looked to investigate whether the pseudo MRM assay could quantify uromodulin in urine samples taken from autosomal-dominant tubulointerstitial kidney disease$U M O D$ (ADTKD-UMOD) patients [22], a clinical situation where urinary uromodulin concentrations are very low [23-26].

Upon submission, it was noted that a similar manuscript detailing an approach for the quantification of uromodulin in human urine by MRM [27], had just been published. In the present manuscript we describe a simple method that enables us to directly deduce surrogate peptides from data-dependent analysis of urine digests allowing the quantification of uromodulin by pseudo MRM analyses on the same instrument. The assay described here is nearly eightfold more sensitive than the most sensitive transition described by the recently published method, and over 20 fold more sensitive than their next sensitive transitions [27]. In

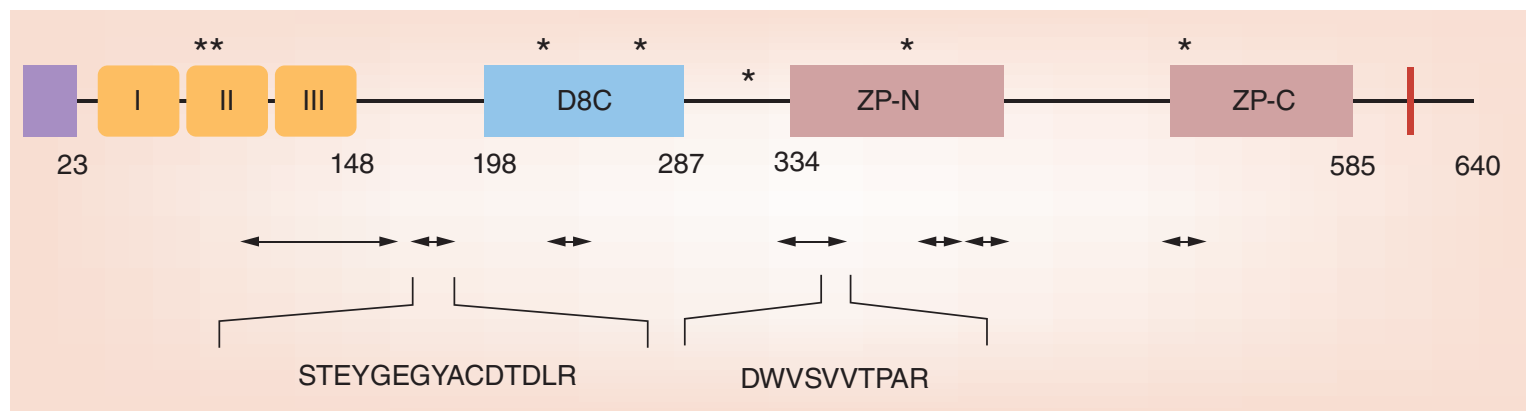

Figure 1. Domain structure of uromodulin. Uromodulin contains a 23 amino acid pre-pro sequence, three epidermal growth-like factor domains (I, II, III), a domain of 8 cysteine residues (D8C), an N-and C-terminal zona pellucida (ZP-N, ZP-C) domain and a glycosylphosphatidylinositol (GPI) anchoring site (red box). Uromodulin has seven experimentally verified N-glycosylation sites at Asn 52, Asn 56, Asn 208, Asn 251, Asn 298, Asn 372 and Asn 489 (marked with asterisks). The arrows represent uromodulin peptides identified following proteolysis of human urine. The peptides STEYGEGYACDTDLR and DWVSVVTPAR were further used for the pseudo MRM assay. 
addition, we validate our method and confirm its biological relevance by comparing uromodulin excretion in a cohort carrying the rs4293393-T or -C $U M O D$ promotor variant and in ADTKD-UMOD patients.

\section{Materials \& methods}

\section{Urine collection}

Mid-flow urine samples were collected either from healthy male volunteers (aged between 25 and 48 years) or from a cohort sample pool of individuals genotyped for their rs4293393 allele variant [19]. The remaining four urine samples analyzed in this study were taken from patients diagnosed with ADTKD$U M O D$, with genotyping confirming patients were of the C77Y [28] or C126R [28] lineages. Urinary uromodulin concentration in these samples was originally quantified by ELISA [29] in the range of $253.8 \mathrm{pM}$ to $2.11 \mathrm{nM}$ [23]. All samples from healthy volunteers were immediately aliquoted and stored at $-80^{\circ} \mathrm{C}$, excepting ten of the 30 samples which underwent several freezethaw cycles and storage at $-80^{\circ} \mathrm{C}$ for 2 years. Samples from ADTKD-UMOD were immediately aliquoted and stored at $-20^{\circ} \mathrm{C}$. All individuals provided informed consent.

\section{Synthesis of stable isotope-labeled} STEYGEGYACDTDLR \& DWVSVVTPAR peptides Stable isotope labeled (SIL) STEYGEGYACDTDLR $\left[{ }^{13} \mathrm{C} 6{ }^{15} \mathrm{~N} 4\right]$ and DWVSVVTPAR $\left[{ }^{13} \mathrm{C} 6{ }^{15} \mathrm{~N} 4\right]$ uromodulin peptides were synthesized and obtained from (Thermo Fisher, Ulm, Germany). The purity of the two peptides was estimated to be approximately $97 \%$ pure and more than $99 \%$ isotopically pure. The precision of the peptide concentration was estimated to be $\pm 25 \%$.

\section{Proteolysis of human uromodulin \& urine for} data-dependent LC-MS/MS analysis

Around $20 \mu \mathrm{g}$ of commercially obtained purified uromodulin from human urine (Millipore, Billerica, MA, USA) was dissolved in $50 \mathrm{mM}$ Tris- $\mathrm{HCl} \mathrm{pH} 8.0$ to a concentration of $1 \mu \mathrm{g} / \mu \mathrm{l}$. Alternatively a $100 \mu \mathrm{l}$ urine aliquot from the frozen pooled human urine was taken. Both the uromodulin and pooled urine samples were reduced with $10 \mathrm{mM}$ dithiothreitol for $1 \mathrm{~h}$ at $37^{\circ} \mathrm{C}$ and alkylated with $50 \mathrm{mM}$ iodoacetamide for $15 \mathrm{~min}$ at room temperature in the dark. Proteins were digested with $2 \mu \mathrm{g}$ trypsin (TPCK-treated, NJ, USA) for $2 \mathrm{~h}$ at $37^{\circ} \mathrm{C}$. A second $2 \mu \mathrm{g}$ aliquot of trypsin was added and the digestion was incubated overnight. The resulting digests were acidified with trifluoroacetic acid (TFA) to a final concentration of $1 \%(\mathrm{v} / \mathrm{v})$. The peptides were desalted on a Microspin C18 cartridge (The Nest Group, MA, USA) according to manufac- turer's instructions. Bound peptides were eluted with $80 \%$ acetonitrile, $0.1 \%$ TFA $(\mathrm{v} / \mathrm{v})$ and dried in a speed vac. The digests were reconstituted in $0.1 \%$ acetic acid, $0.005 \%$ TFA (v/v) (solvent A) for LC-MS/MS analysis (see below).

\section{Data-dependent LC-MS/MS analysis}

For data-dependent analyses, uromodulin or urine digests were analyzed by capillary LC-MS/MS as previously described [30]. A $0.075 \mathrm{~mm} \times 150 \mathrm{~mm}$ column (New Objectives, MA, USA) was packed in-house with Reprosil C18 reverse-phase material $(2.4 \mu \mathrm{m}$ particle size, Dr Maisch, Ammerbuch-Entringen, Germany) and connected to the inlet of an Orbitrap FT hybrid mass-spectrometer (Thermo Scientific, Reinach, Switzerland). The solvents used for chromatographic separation of peptides were solvent A and solvent B (0.1\% acetic acid, $0.005 \%$ TFA, $80 \%$ acetonitrile $[\mathrm{v} / \mathrm{v}])$. Around 50 fmols of uromodulin digest or $2 \mu \mathrm{g}$ urine digest were injected using a Proxeon nLC capillary pump (Thermo Scientific) set to $300 \mathrm{nl} / \mathrm{min}$. Chromatographic separation of peptides was achieved using a linear gradient from 0 to $40 \%$ solvent B in solvent A over $95 \mathrm{~min}$. Following this, the percentage of solvent $B$ was increased to $75 \%$ in 10 min and was maintained for $15 \mathrm{~min}$ before equilibration of the column to $0 \%$ solvent B. Eluting peptides were ionized at $2.5 \mathrm{kV}$ and the mass-spectrometer was operated in data-dependent mode. Precursor scans were performed in the Orbitrap with the resolution set to 60,000 and fragment ions were mass analyzed in the LTQ instrument. A top ten method was run so that the ten most intense precursor ions were selected for fragmentation. Resulting MS/MS spectra were searched against the SwissProt databank (taxonomy set to $H$. sapiens) with Proteome Discoverer 1.4 (Thermo Scientific) using Mascot (Matrix Science, London, UK) as the search engine. Precursor ion tolerance was set to $10 \mathrm{ppm}$ and fragment ion tolerance to 0.5 Da. Carbamidomethylation of cysteine residues were set to fixed and oxidation of methionine residues were selected as variable modifications, respectively. Peptide search matches were filtered to $1 \%$ false-discovery rate (high confidence).

\section{Quantification of uromodulin in human urine by pseudo MRM}

Stored human urine samples were thawed and 10 or $100 \mu \mathrm{l}$ aliquots of urine were reduced and alkylated as above. Urinary proteins in the $10 \mu \mathrm{l}$ assay were digested with $0.2 \mu \mathrm{g}$ endoproteinase Lys-C at $37^{\circ} \mathrm{C}$ for $2 \mathrm{~h}$ before addition of a further $0.2 \mu \mathrm{g}$ for $2 \mathrm{~h}$. Further digestion was performed with $0.2 \mu \mathrm{g}$ trypsin for $2 \mathrm{~h}$ at $37^{\circ} \mathrm{C}$ followed by a second addition of $0.2 \mu \mathrm{g}$ trypsin and incubation overnight. For the $100 \mu$ assay, 
samples were digested using the same procedure but 2 $\mu \mathrm{g}$ of the proteases were used. The digests were acidified with TFA to $1 \%$ final concentration and the peptides were desalted on a Microspin C18 cartridge (The Nest Group) according to manufacturer's instructions. Bound peptides were eluted with $80 \%$ acetonitrile, $0.1 \%$ TFA (v/v) and dried in a speed vac. The $10 \mu \mathrm{l}$ urine digest was dried completely, while evaporating the $100 \mu \mathrm{l}$ digest completely was found to strongly interfere with peptide recovery. Therefore the $100 \mu \mathrm{l}$ urine digests were evaporated to approximately $30 \mu \mathrm{l}$. All samples were then restored to $60 \mu \mathrm{l}$ volume through addition of $0.1 \%$ acetic acid, $0.005 \%$ TFA (v/v) before injection to the mass spectrometer.

To establish a calibration curve, urine from three healthy males was pooled, and from this two assays for 10 and $100 \mu \mathrm{l}$ urine aliquots were developed. For the $10 \mu \mathrm{l}$ assay, SIL-STEYGEGYACDTDLR and SIL-DWVSVVTPAR peptides ranging from 250 to $4000 \mathrm{nM}$ (eight calibration points) were spiked into $10 \mu \mathrm{l}$ urine digested with endoproteinase Lys-C and trypsin prior to sample desalting. For the $100 \mu \mathrm{l}$ assay, SIL peptides ranging from 1 to $250 \mathrm{nM}$ (ten calibration points) were spiked into $100 \mu \mathrm{l}$ urine digests. Quality control (QC) samples used in the $10 \mu \mathrm{l}$ assay were generated through spiking SIL peptides into urine digests at 250, 1000 and $4000 \mathrm{nM}$ concentrations ( $\mathrm{n}=5$ for each batch of samples run). QC samples used in the $100 \mu \mathrm{l}$ assay were generated through spiking SIL peptides into urine digests at 1 , 10,100 and $250 \mathrm{nM}$ concentrations $(\mathrm{n}=5$ for each batch of samples run).

The 10 and $100 \mu \mathrm{l}$ urine digests spiked with the SIL peptides were analyzed by capillary LC-MS/MS as above. The LTQ Orbitrap instrument was operated in a pseudo MRM mode. For this, the high-resolution Orbitrap scanned in selected ion monitoring (SIM) mode at 7500 resolution around the isotope clusters of the doubly charged STEYGEGYACDTDLR and SIL-STEYGEGYACDTDLR peptides $(\mathrm{m} / \mathrm{z} 868.00$ to 872.00 and 873.00 to 876.00 , respectively). Likewise, the SIM scan was applied to the doubly charged DWVSVVTPAR and SIL-DWVSVVTPAR peptides $(\mathrm{m} / \mathrm{z} 565.00$ to 568.00 and 570.00 to 573.00 , respectively). The LTQ part of the instrument was set to fragment the STEYGEGYACDTDLR, and SILSTEYGEGYACDTDLR peptides $(\mathrm{m} / \mathrm{z} 868.86$ and $873.86)$ and scanning the fragment ions from 250 to $1600 \mathrm{~m} / \mathrm{z}$. For the DWVSVVTPAR and SIL-DWVSVVTPAR pair, the LTQ was set to the corresponding precursor $\mathrm{m} / z s$ (565.31 and 570.31) and the fragment ions were recorded between 155 to $1200 \mathrm{~m} / \mathrm{z}$. The normalized collision energy was set to 35 for all peptides and the isolation width of the LTQ was $1.0 \mathrm{~m} / \mathrm{z}$.

\section{Quantification of uromodulin}

Endogenous and SIL STEYGEGYACDTDLR and DWVSVVTPAR peptides were located in the chromatogram by extracting the selected ion tracings from the SIM scans with $10 \mathrm{ppm}$ mass tolerance. The elution position of the two peptide precursors was checked by overlaying the precursor ions with selected fragment ions or by checking the entire fragmentation spectra. The peaks corresponding to the correct precursors from the SIM scans were then integrated using Xcalibur ${ }^{\mathrm{TM}}$ software version 2.1 (Thermo Scientific, Bremen, Germany). Linear regression lines were calculated for the generation of calibration curves. From these calibration curves, the SIL peptide concentrations of the QC samples were calculated. Calibration curves and QC samples were generated for each batch of clinical urine samples assayed using the $10 \mu \mathrm{l}$ assay (three batches) and for the $100 \mu \mathrm{l}$ assay (one batch). The accuracy in QC measurement was ascertained by the following equation: percent accuracy $=(A / B) \times 100$, whereas $A$ is the concentration of the SIL peptide in the QC sample calculated from the calibration curve, and B is the known concentration of SIL peptide spiked into the QC sample. Percent precision was calculated through assessment of the coefficient of variation of the five QC replicates multiplied by 100 . The lower limit of quantification (LLOQ) of the $10 \mu \mathrm{l}$ assay was defined as a sample in which the mean accuracy and precision of the QC samples over the three batches were $100 \pm 25 \%$ and $\leq 25 \%$ respectively.

Concentration of uromodulin in clinical urine samples was quantified through ascertaining the relative ratio of the endogenous peptide by the spiked in peptide, and then multiplication by the spiked SIL peptide concentration. A mean was taken between the values achieved by the STEYGEGYACDTDLR and DWVSVVTPAR peptides.

\section{ELISA analysis of uromodulin concentration in human urine}

ELISAs undertaken in this work were performed as previously described [10]. A sheep anti-human uromodulin antibody (Meridan Life Science, TN, USA) was used as the capture antibody, a mouse monoclonal anti-human Tamm-Horsfall protein antibody (Cedarlane Laboratories, NC, USA) as the primary antibody, and a goat anti-mouse $\operatorname{IgG}(\mathrm{H}+\mathrm{L})$ horseradish peroxidase-conjugated protein (Bio-Rad Laboratories Inc., CA, USA) as a secondary antibody. The calibration curve was established using human uromodulin (stock solution: $100 \mu \mathrm{g} / \mathrm{ml}$; END, CA, USA). The assay was found to have a limit of detection of $42.8 \mathrm{pM}$ and linearity of 1.0. The 
Table 1. Identified uromodulin fragments from the data-dependent analysis of human urine.

\begin{tabular}{|c|c|c|c|c|c|}
\hline Sequence & $\mathrm{MH}+$ & Charge & $m / z$ & $\begin{array}{l}\text { Mascot ion } \\
\text { score }\end{array}$ & $\Delta$ ppm \\
\hline${ }^{186}$ STEYGEGYACDTDLR ${ }^{200}$ & 1736.7225 & 2 & 868.86487 & 109 & 8.97 \\
\hline${ }^{437}$ TALQPMVSALNIR ${ }^{449}$ & 1413.8003 & 2 & 707.40381 & 84 & 8.5 \\
\hline${ }^{450}$ VGGTGMFTVR ${ }^{459}$ & 1024.5307 & 2 & 512.76898 & 79 & 6.05 \\
\hline${ }^{589}$ SGSVIDQSR ${ }^{597}$ & 948.4809 & 2 & 474.74411 & 75 & 6.75 \\
\hline${ }^{532}$ DSTIQVVENGESSQGR ${ }^{547}$ & 1705.8122 & 3 & 569.27557 & 75 & 7.82 \\
\hline${ }^{143}$ GDGWHcEcSPGScGPGLDcVPEGDALVcADPcQAHR ${ }^{178}$ & 3983.6090 & 4 & 996.65771 & 65 & 9.32 \\
\hline${ }^{351}$ SLGFDKVFMYLSDSR ${ }^{365}$ & 1764.8765 & 2 & 882.94189 & 61 & 7.88 \\
\hline${ }^{376}$ DWVSVVTPAR ${ }^{385}$ & 1129.6089 & 2 & 565.30811 & 55 & 7.83 \\
\hline${ }^{357}$ VFMYLSDSR ${ }^{365}$ & 1117.5431 & 2 & 559.27521 & 55 & 7.55 \\
\hline${ }^{366}{ }^{C S G G N D R}{ }^{372}$ & 855.3483 & 2 & 428.17776 & 47 & 7.99 \\
\hline${ }^{548} \mathrm{FSVQMFR}{ }^{554}$ & 914.4619 & 2 & 457.73459 & 45 & 7.18 \\
\hline${ }^{598}$ VLNLGPITR $^{606}$ & 982.6114 & 2 & 491.80933 & 42 & 7.06 \\
\hline${ }^{437} T A L Q P m V S A L N I R{ }^{449}$ & 1429.7955 & 2 & 715.40179 & 41 & 8.55 \\
\hline${ }^{520}{ }^{\text {YFIIQDR }}{ }^{526}$ & 954.5104 & 2 & 477.75882 & 38 & 6.28 \\
\hline${ }^{179} T_{L D E Y W R}{ }^{185}$ & 982.46874 & 2 & 491.73801 & 35 & 5.94 \\
\hline
\end{tabular}

Lower case c represents carbamidomethylated cysteine residue, and lower case $m$ represents an oxidized methionine residue. Peptides marked in bold represent the surrogate peptides used in the quantification of uromodulin in human urine.

inter- and intra-assay variation were 3.28 and $5.46 \%$ respectively. The quantifiable range of the assay was between $57.35 \mathrm{pM}$ and $7.35 \mathrm{nM}$ uromodulin concentration.

\section{Quantification of urinary creatinine concentration}

For investigating the effect of the UMOD genotype, uromodulin concentrations measured by both ELISA and pseudo MRM assays were normalized to urinary creatinine. This was to control for inter-individual variations in urine dilution. Urinary creatinine was measured using the Syncron ${ }^{\circledR}$ System Creatinine Assay (Unicell Dxc Syncron ${ }^{\circledR}$, Beckman Coulter, CA, USA).

\section{Statistical analysis}

All statistical analyses were undertaken using GraphPad Prism Version 5.04 (GraphPad Software, CA, USA). To assess correlation between data, a linear regression line was drawn, with the slope measured. Goodness of fit of the data to the line was assessed by the $r^{2}$ value. To ascertain whether a statistical difference in the urinary uromodulin concentration normalized to creatinine between the CC and TT genotypes was evident, a Shapiro-Wilk test was used to confirm the data followed a normal distribution. Consequently a Mann-Whitney test was used to identify significant differences between the genotypes.

\section{Results}

\section{Selection of uromodulin peptides for pseudo}

MRM

To select suitable peptide candidates usable for quantification, we first analyzed individual digests of human uromodulin by data-dependent LC-MS/MS on an Orbitrap instrument to obtain proteotypic peptides reproducibly detected with large signal and good sequence coverage. For this, human urine from a pool of healthy individuals was reduced, alkylated and subsequently digested using a combination of endoproteinase Lys-C and trypsin. From the LC-MS/MS analysis, 92 proteins were identified by Proteome Discoverer with uromodulin (or Tamm-Horsfall urinary glycoprotein, SwissProt Accesssion P07911) ranked at position 4 (data not shown). For uromodulin, 16 peptides were identified (Table 1), covering $25 \%$ of the protein's sequence. These peptides were found to span all domains of uromodulin (Figure 1).

From this list, two uromodulin peptides were selected as surrogate peptides for the protein's quantification. Peptides containing methionines and glutamines were excluded due to their potential for oxidation and deamination [31]. Furthermore, peptides with a charge greater than +2 were also not selected as such fragmentation spectra are sometimes not particularly rich in fragment ions. Consequently, the STEYGEGYACDTDLR and DWVSVVTPAR peptides were selected for the quantification of uromodulin. Neither of these two peptides 
contained a site of known N-glycosylation (Figure 1) and both yielded intense fragment ions (Figure 2A \& B), supporting the utility of these peptides as surrogates for the quantification of uromodulin in human urine. Following selection of these peptides, SIL peptides of the same sequence but labeled at the $\mathrm{C}$-terminal arginine using $6 \mathrm{C}^{13}$ and $4 \mathrm{~N}^{15}$ isotopes were synthesized. This labeling resulted in a +10 Da mass shift compared with their unlabeled counterparts.

\section{Pseudo MRM method development \& assay} validation

Following selection of the two surrogate peptides for the quantification of uromodulin in urine, an MRM-like

(A)

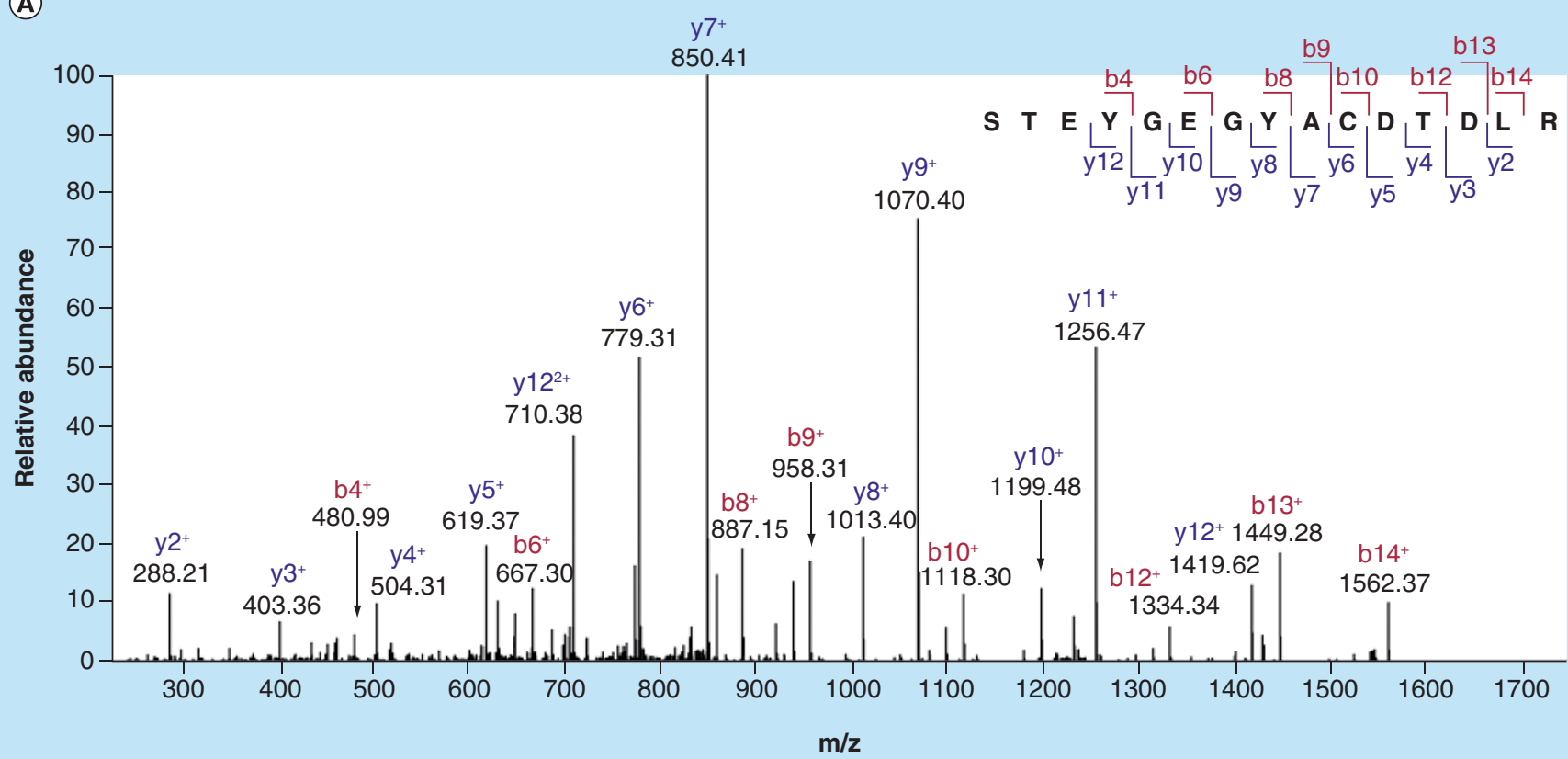

(B)
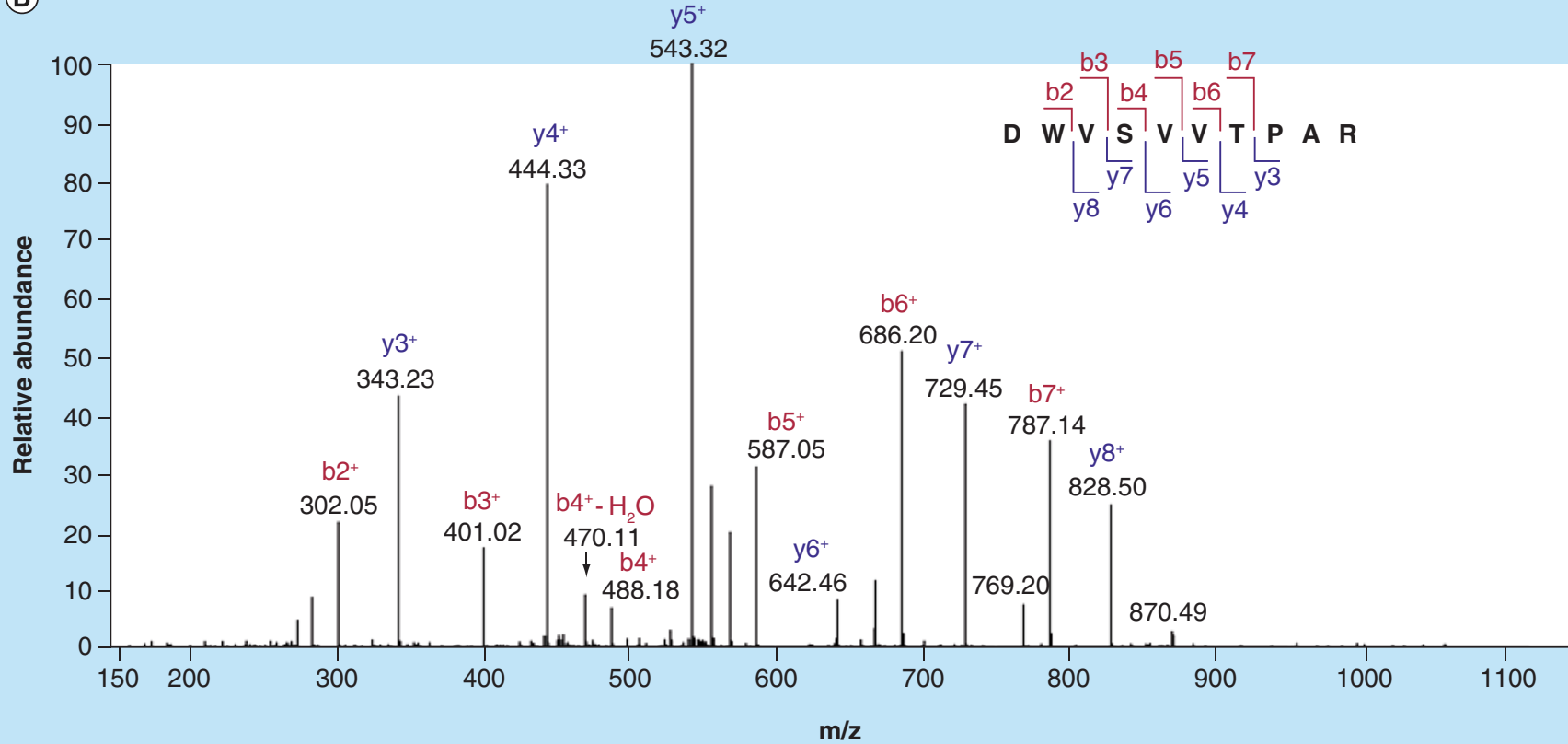

Figure 2. Fragmentation of the human uromodulin peptides used for quantification. Fragmentation spectra of the STEYGEGYACDTDLR (A) and DWVSVVTPAR (B) peptide fragments identified from human urine tryptic digests. The observed b and y ions are labeled in red and blue, respectively. 
(pseudo MRM) scanning method on an LTQ Orbitrap instrument was developed. A SIM scan around the isotope cluster of both the endogenous and SIL forms of both peptides was set (Table 2). The ion trap (LTQ) of the instrument was set to fragment only the doubly charged endogenous and SIL precursors of the peptides with a fixed fragment ion scan range set to cover the most prominent fragment ions (Table 2).

These pseudo MRM scan parameters were tested by spiking the two SIL peptides into $10 \mu$ l of digested pooled human urine to a final concentration of $100 \mathrm{nM}$, with tandem mass-spectrometric (MS/MS) analysis using the scanning parameters outlined above. The resulting chromatogram was relatively complex (Figure 3A), despite targeted SIM scanning. To locate the position of the two uromodulin peptides, the $\mathrm{m} / \mathrm{z}$ for the doublycharged endogenous and SIL STEYGEGYACDTDLR and DWVSVVTPAR pairs were extracted with $10 \mathrm{ppm}$ tolerance. Both pairs were unambiguously located in the chromatogram (left panels of Figure $3 \mathrm{~B}-\mathrm{E}$ ) and the fragment spectra perfectly matched the sequence of the two peptides with the expected $10 \mathrm{Da}$ shift of the y-ions for the SIL peptides (right panels of Figure 3B-E). The selected ion chromatograms showed that the doubly charged STEYGEGYACDTDLR uromodulin peptide constituted the major peak $(57.32 \mathrm{~min})$ in the total ion chromatogram, while the second DWVSVVTPAR peptide produced a less intense, but still a pronounced peak at $70.54 \mathrm{~min}$ (Figure 3A). Interestingly, a very slight shift in retention time of the SIL peptides compared with their endogenous counterparts was noticeable (Figure 3B-E). Also, the ratio of the intensities for the endogenous and SIL peptides was approximately the same for the two pairs, indicating that both peptides were equally well liberated during the digestion of uromodulin.

For the calibration curve, SIL peptides were spiked into digested human urine at final concentrations of between 100-4000 nM ( 9 points, Figure 4A) and analyzed by pseudo MRM. The $\mathrm{r}^{2}$ value for the SILSTEYGEGYACDTDLR peptide calibration curve was $0.9953 \pm 0.0041$ (mean \pm StDev), and for the SILDWVSVVTPAR was $0.9897 \pm 0.0065$ (mean \pm StDev).

In order to achieve confidence in the reproducibility and accuracy of the $10 \mu \mathrm{l}$ assay, as well as defin- ing its LLOQ, the guidelines of the US Food and Drug Administration (FDA) and recommendations by Carr et al. [32,33] were followed. The LLOQ of the $10 \mu \mathrm{l}$ assay (interassay accuracy of $100 \pm 25 \%$ and precision $\leq 25 \%$ ) was $250 \mathrm{nM}$. Interday mean accuracy of $100 \pm 20 \%$ and precision of $\leq 20 \%$ for the 1000 and $4000 \mathrm{nM}$ QC samples provides further confidence in the reliability of the assay (Table 3). In order to quantify urinary uromodulin concentration below $250 \mathrm{nM}$ concentration an assay for $100 \mu \mathrm{l}$ urine was developed.

Upon development of a calibration curve for the $100 \mu \mathrm{l}$ urinary uromodulin assay it was found that evaporating samples to complete dryness after desalting the digest meant a linear curve was unachievable. We hypothesize that this is a consequence of hindrance from a moiety not removed by desalting (matrix effect). This interference could be resolved to some extent through evaporating samples to approximately $30 \mu \mathrm{l}$ volume, and subsequently restoring all samples to $60 \mu \mathrm{l}$ volume through addition of $0.1 \%$ acetic acid, $0.005 \%$ TFA (v/v). This allowed a calibration curve between 1 and $200 \mathrm{nM}$ to be achieved for SIL-STEYGEGYACDTDLR $\left(r^{2}=0.9896,9\right.$ points $)$ and between 1 and $250 \mathrm{nM}$ for SIL-DWVSVVTPAR $\left(r^{2}=0.9723,10\right.$ points) (Figure 4B). However, when assessing the precision values of QC samples it was noted that the assay was variable (data not shown), and therefore validation of the assay as undertaken by the $10 \mu \mathrm{l}$ assay could not be achieved. We suspect that to some extent that this may be a consequence of error in attempting to reconstitute partially dried samples to a universal $60 \mu \mathrm{l}$ volume. As the same aliquoted pooled-urine had been used throughout this work, we hypothesized that normalizing the area under the curve (AUC) of the SIL-STEYGEGYACDTDLR and SIL-DWVSVVTPAR peptides to their endogenous versions released through tryptic digest of the urine matrix would remove this error from the method. This approach allowed an optimal linear standard curve for both SIL-STEYGEGYACDTDLR $\left(\mathrm{r}^{2}=\right.$ $0.9994,10$ points $)$ and SIL-DWVSVVTPAR $\left(\mathrm{r}^{2}\right.$ $=0.9848,10$ points) between 1 and $250 \mathrm{nM}$ to be achieved (Figure 4C). Furthermore, also normalizing the QC samples in the same way meant that the intra-

Table 2. Operating parameters for the pseudo multiple reaction monitoring assay.

\begin{tabular}{|llll|}
\hline Peptide & SIM scan range & Parent ion $\mathbf{~} / \mathbf{z}$ & MS2 scan range \\
\hline STEYGEGYACDTDLR & $868.0-872.0$ & 868.8625 & $250-1600$ \\
\hline STEYGEGYACDTDLR* & $873.0-876.0$ & 873.8648 & $240-1600$ \\
\hline DWVSVVTPAR & $565.0-568.0$ & 565.3042 & $155-1200$ \\
\hline DWVSVVTPAR* & $570.0-573.0$ & 570.3081 & $155-1200$ \\
\hline$R^{*}$ represents a $\left.{ }^{13}{ }^{*} 6^{15} \mathrm{~N} 4\right]$ labeled arginine residue. & & \\
\hline
\end{tabular}




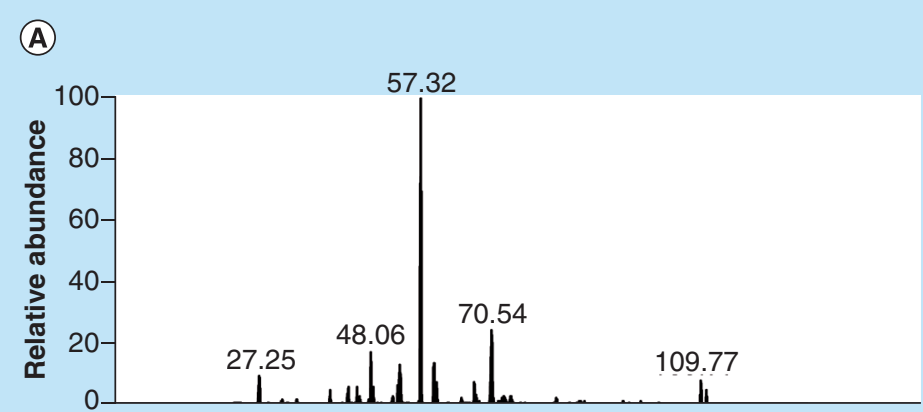

(B)
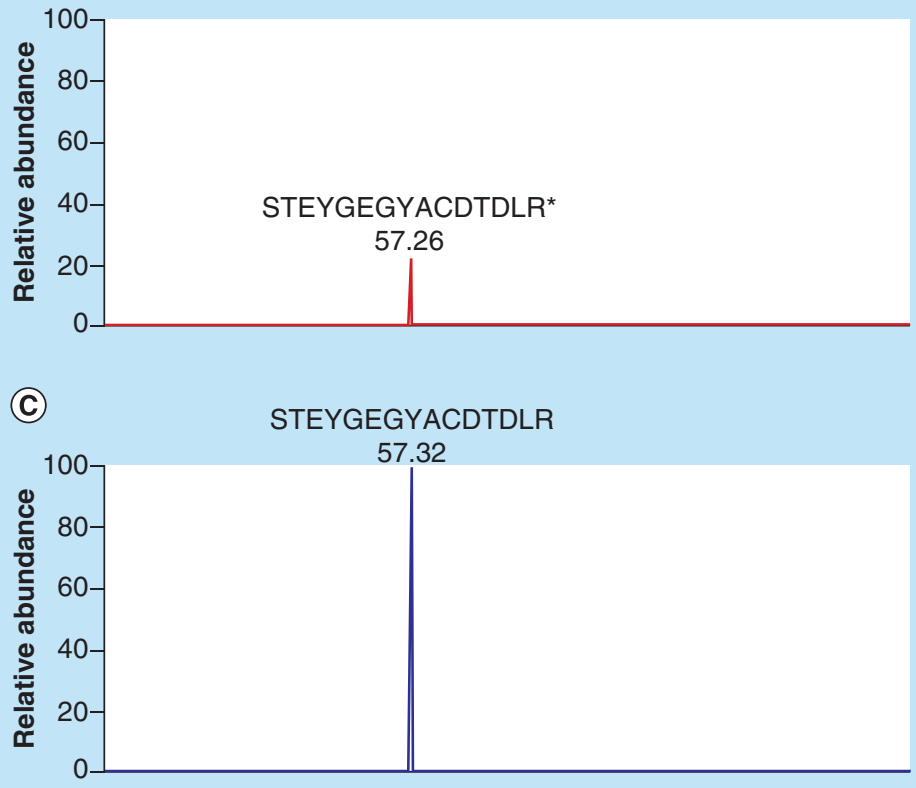

(D)
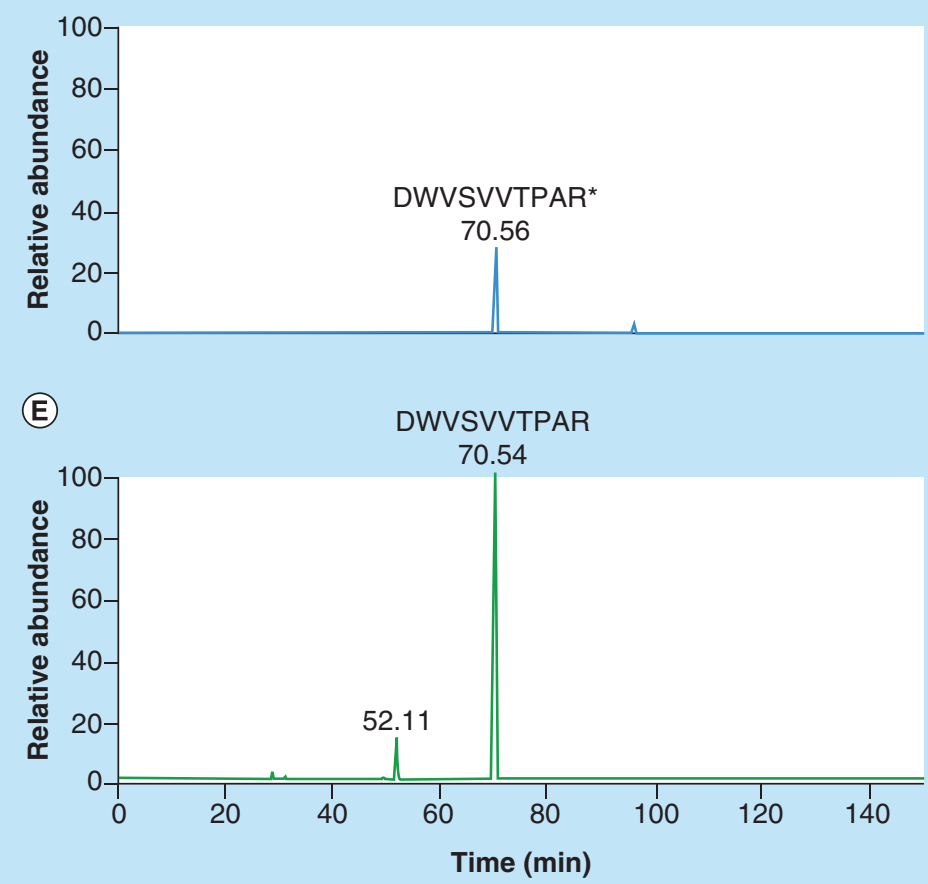
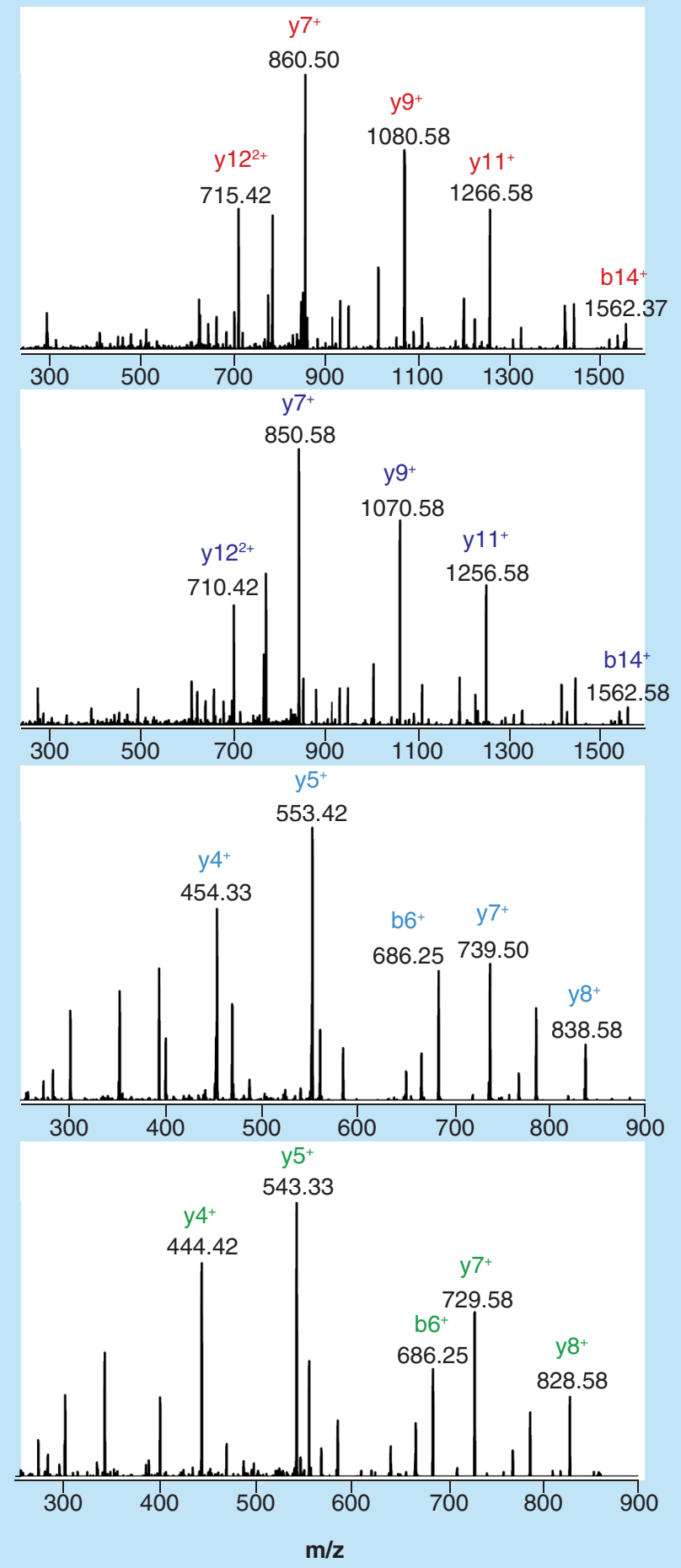
Figure 3. Pseudo multiple reaction monitoring of uromodulin in human urine (see facing page). (A) Total ion count of a digest of $10 \mu \mathrm{l}$ pooled human urine recorded with a pseudo MRM. Extracted ion chromatograms of (B) the SIL-STEYGEGYACDTDLR ( $m / z$ 873.86) and (C) endogenous STEYGEGYACDTDLR ( $\mathrm{m} / \mathrm{z}$ 868.86), (D) SIL-DWVSVVTPAR ( $\mathrm{m} / \mathrm{z} 570.31)$ and (E) endogenous DWVSVVTPAR $\left(\mathrm{m} / \mathrm{z}\right.$ 565.30) doubly charged peptides. The corresponding fragmentation spectra are shown in the right panels. $R^{*}$ represents a $\left[{ }^{13} \mathrm{C} 6{ }^{15} \mathrm{~N} 4\right]$ labeled arginine residue.

assay validation could be undertaken in accordance with the guidelines of the FDA and Carr et al. $[32,33]$. The LLOQ of the $100 \mu \mathrm{l}$ assay (intra-assay accuracy of $100 \pm 25 \%$ and precision $\leq 25 \%$ ) was $1 \mathrm{nM}$ for STEYGEGYACDTDLR and $10 \mathrm{nM}$ for DWVSVVTPAR. Intra-assay mean accuracy of $100 \pm 20 \%$ and precision of $\leq 20 \%$ for the 100 and $250 \mathrm{nM}$ QC samples provides further confidence in the reliability of the assay (Table 4).

Further investigations into the matrix effect of urine in the $100 \mu \mathrm{l}$ assay were undertaken by comparing the intensity of equimolar amounts of SIL-STEYGEGYACDTDLR spiked into either 100 $\mu \mathrm{l}$ digested pooled urine, or $50 \mathrm{mM}$ Tris buffer $\mathrm{pH}$ 8.0 alone, or purified uromodulin stored in $50 \mathrm{mM}$ Tris buffer $\mathrm{pH} 8.0$ (Figure 4C). While the resulting AUC for the signal for the SIL-STEYGEGYACDTDLR peptide was similar for the endogenous uromodulin peptide and the $50 \mathrm{mM}$ Tris buffer spike-in, an approximate tenfold loss in signal occurred when SIL-STEYGEGYACDTDLR was spiked into digested human urine.
(A)

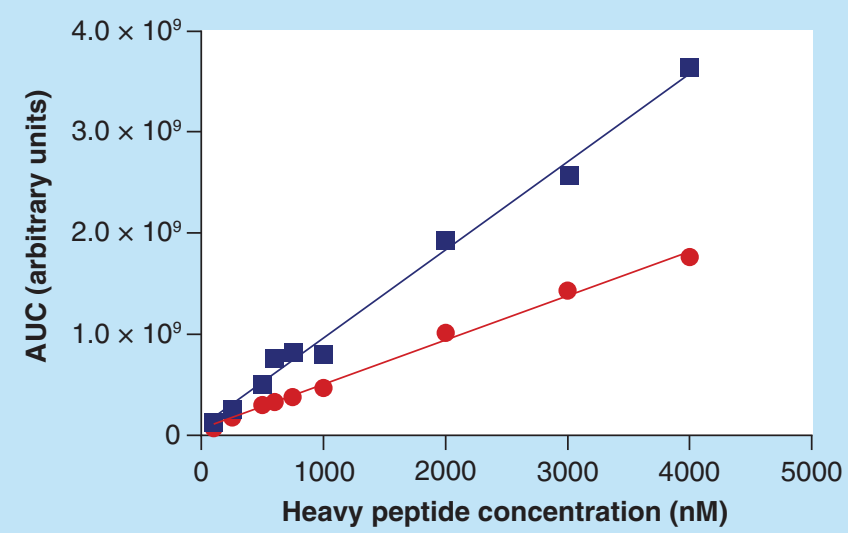

(c)

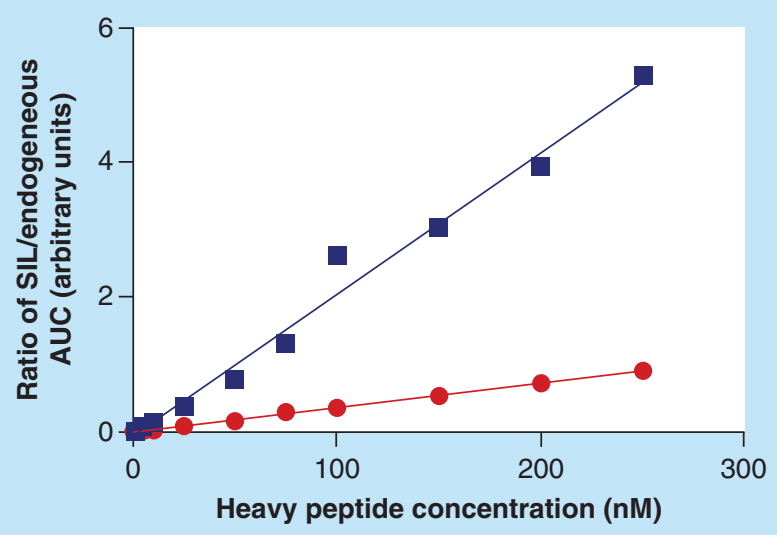

(B)

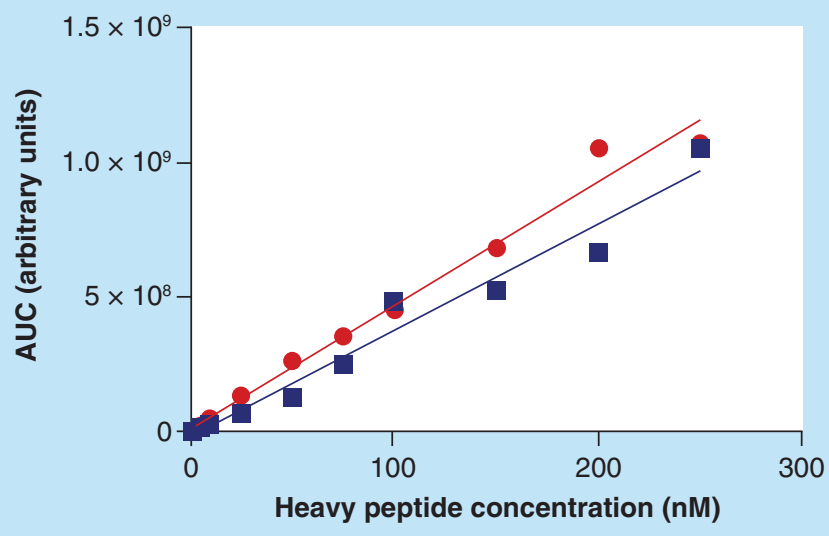

(D)

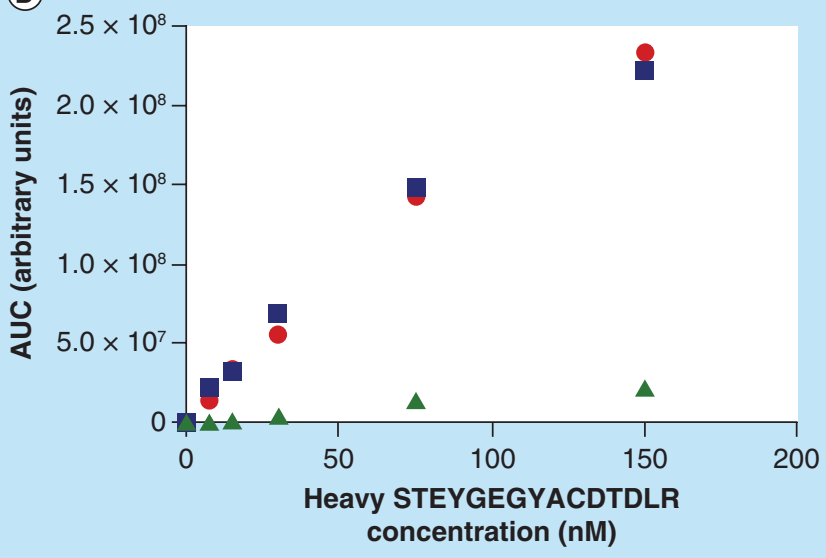

Figure 4. Calibration curves for the SIL peptides spiked into $10 \mu \mathrm{l}$ and $100 \mu$ digested urine. Increasing concentrations of the SIL surrogate peptides were spiked into (A) 10 or (B) $100 \mu$ l digested human urine and measured by the pseudo MRM method. STEYGEGYACDTDLR (red circles, $r^{2}=0.9947$ for the $10 \mu \mathrm{l}$ assay and 0.9793 for the $100 \mu \mathrm{l}$ assay, respectively). DWVSVVTPAR (blue squares, $r^{2}=0.9924$ for the $10 \mu$ lassay and 0.9723 for the $100 \mu$ l assay, respectively). Representative experiments are shown. (C) Around $100 \mu \mathrm{l}$ calibration curve when AUC of SIL-peptides is normalized to their endogenous counterparts. STEYGEGYACDTDLR (red circles, 0.9994). DWVSVVTPAR (blue squares, $\left.r^{2}=0.9848\right)$. (D) Increasing concentrations of SIL-STEYGEGYACDTDLR was spiked into $100 \mu$ l digested urine (green triangles), or $50 \mathrm{mM}$ Tris-buffer pH 8 (red circles), or into a digest of purified uromodulin dissolved in $100 \mu \mathrm{l} 50 \mathrm{mM}$ Tris-buffer $\mathrm{pH} 8$ (blue squares). 


\begin{tabular}{|c|c|c|c|c|}
\hline & \multicolumn{2}{|c|}{ Accuracy, \% ( \pm StDev) } & \multicolumn{2}{|c|}{ Precision (\%) } \\
\hline & STEY & DWV & STEY & DWV \\
\hline \multirow[t]{2}{*}{ QC1 } & 118.42 & 124.71 & 12.11 & 8.51 \\
\hline & $( \pm 14.34)$ & $( \pm 10.61)$ & & \\
\hline \multirow[t]{2}{*}{ QC2 } & 107.96 & 100.43 & 14.38 & 12.93 \\
\hline & $( \pm 15.53)$ & $( \pm 12.99)$ & & \\
\hline \multirow[t]{2}{*}{ QC3 } & 104.23 & 100.36 & 12.10 & 16.36 \\
\hline & $( \pm 12.61)$ & $( \pm 16.43)$ & & \\
\hline
\end{tabular}

One concern in quantifying proteins through the tryptic release of surrogate peptides is the potential for peptide degradation over the digestion period, resulting in the introduction of bias into the quantification method. To test peptide degradation throughout the digestion period the SIL peptides (at final concentrations of 250, 1000 and $4000 \mathrm{nM}, \mathrm{n}=5$ ) were spiked into $10 \mu \mathrm{l}$ reduced and alkylated urine immediately prior to addition of the endoproteinase Lys-C, and compared with samples where SIL peptides were added at the end of the digestion process immediately prior to desalting. No significant difference in the AUCs from the extracted pseudo MRM traces from either peptide was observed throughout the digestion process (Supplementary Figure 1). To ensure that no loss of peptides occurred when the samples are held in the auto sampler throughout LCMS/MS analysis of the batches, all QC samples in the $10 \mu \mathrm{l}$ assay $(250,1000$ and $4000 \mathrm{nM}$ SIL peptide concentrations, $\mathrm{n}=5$ for each batch) were assayed at the start of the batch, and then re-analyzed at the end. Again no significant differences in the AUCs from the extracted pseudo MRM traces of the SIL peptides could be detected throughout the run (data not shown).
Validation of the surrogate peptides for the quantification of urinary uromodulin concentration in individuals exhibiting TT or CC genotype

It is almost universally recommended to use more than one surrogate peptide in the absolute quantification of proteins by MS. This approach allows rapid identification of any peptide specific issues with the potential for influencing protein quantification. Analysis of the 30 samples in the cohort revealed a good correlation $\left(\mathrm{r}^{2}=\right.$ 0.8696 , slope $=1.0408$ ) in urinary uromodulin quantification using either the STEYGEGYACDTDLR or the DWVSVVTPAR surrogate peptides (Figure 5A). Discrepancy in one point is evident from this correlation analysis, where STEYGEGYACDTDLR is quantified at $1606 \mathrm{nM}$ concentration, and DWVSVVTPAR is quantified at $1279 \mathrm{nM}$ concentration. While this difference is within the stipulated $20 \%$ accuracy criteria of the assay, it is most likely a consequence of human handling. The similar quantification of urinary uromodulin by both peptides provides confidence in their suitability as surrogates for the protein. For the assessment of urinary uromodulin concentration in this cohort of 30 individuals a mean value between these two peptides was calculated.

Table 4. Intraday assay validation parameters from the $100 \mu$ uromodulin quantification assay.

\begin{tabular}{|c|c|c|c|c|}
\hline & & $\% \pm$ StDev) & & on (\%) \\
\hline & STEY & DWV & STEY & DWV \\
\hline QC1 & $\begin{array}{l}124.46 \\
( \pm 16.06)\end{array}$ & $\begin{array}{l}361.22 \\
( \pm 10.85)\end{array}$ & 12.90 & 3.00 \\
\hline QC2 & $\begin{array}{l}103.78 \\
( \pm 9.32)\end{array}$ & $\begin{array}{l}114.57 \\
( \pm 7.82)\end{array}$ & 8.98 & 6.82 \\
\hline QC3 & $\begin{array}{l}106.12 \\
( \pm 4.71)\end{array}$ & $\begin{array}{l}115.68 \\
( \pm 22.57)\end{array}$ & 4.44 & 19.49 \\
\hline QC4 & $\begin{array}{l}86.15 \\
( \pm 8.35)\end{array}$ & $\begin{array}{l}100.65 \\
( \pm 17.206)\end{array}$ & 9.69 & 17.10 \\
\hline
\end{tabular}


Quantification of urinary uromodulin concentration in individuals exhibiting either TT or CC genotype

Following validation of the pseudo MRM method for the quantification of uromodulin in human urine, the method was used to quantify urinary uromodulin concentration in a cohort of individuals previously assessed for their $U M O D$ rs 4293393 genotype [20]. Data achieved by the pseudo MRM assay were then compared and contrasted with that of an established ELISA [10]. Out
(A)

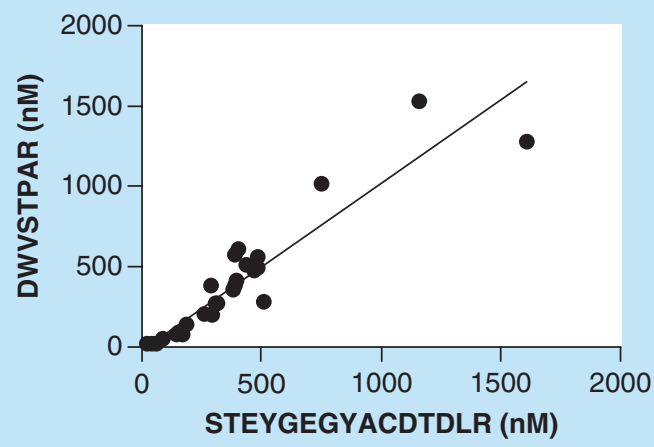

(C)

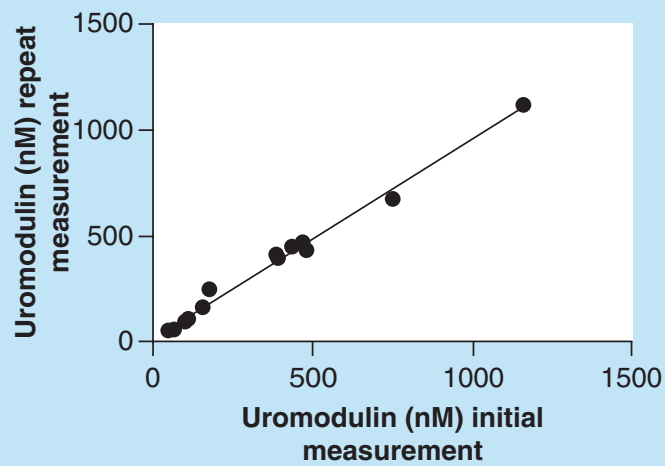

(E)
(B)

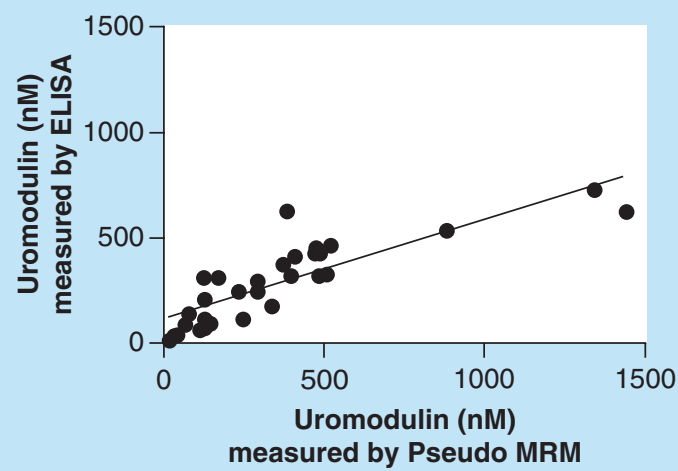

(D)

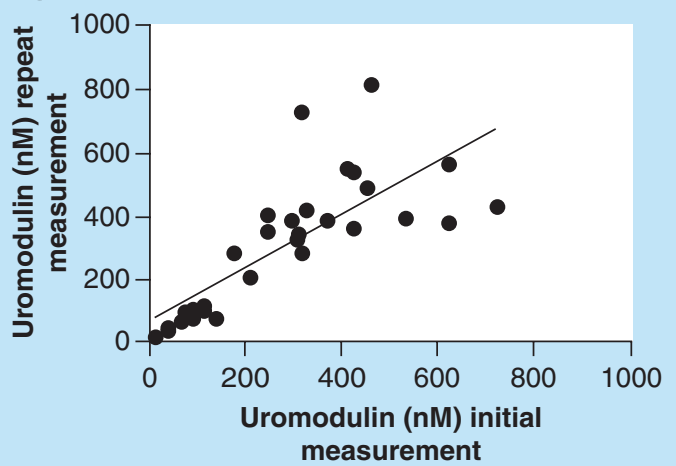

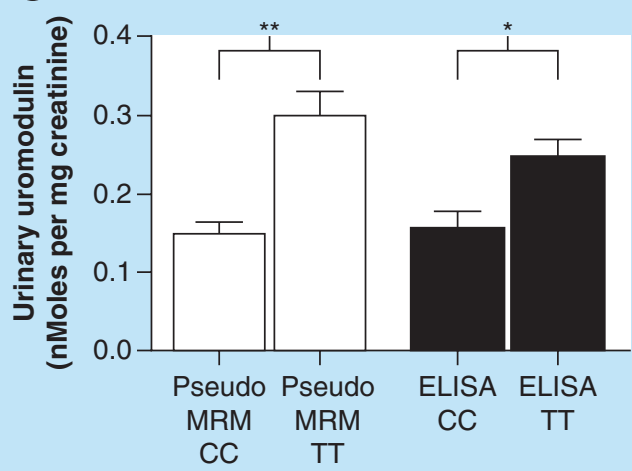

Figure 5. Quantification of urinary uromodulin in human urine samples by pseudo multiple reaction monitoring and ELISA. (A) Correlation of urinary uromodulin concentration in all samples when measured by STEYGEGYACDTDLR or DWVSVVTPAR in both genotypes. Correlation $\left(r^{2}=0.8696\right.$, slope $\left.=1.0408\right)$. (B) Correlation of urinary uromodulin concentration in all samples when measured by pseudo MRM or ELISA $\left(r^{2}=0.7038\right.$, slope $=0.471$ ). (C) Reproducibility of the pseudo MRM when urinary uromodulin concentration was reassessed in two independent assays. Correlation $\left(r^{2}=0.9903\right.$, gradient $\left.=0.9391, n=13\right)$. (D) Reproducibility of the ELISA method when urinary uromodulin concentration was reassessed in two independent assays. Correlation $\left(r^{2}=0.5895\right.$, slope $=0.8332, n=30$ ). (E) Effect of the promoter variant $r s 4293393$ of UMOD on urinary uromodulin concentration as measured by pseudo MRM and ELISA ( $n=11$ for CC, $n=19$ for TT genotypes). Data represented as mean ( \pm StDev). ${ }^{*} \mathrm{p} \leq 0.02 ;{ }^{* *} \mathrm{p} \leq 0.002$ 
of the 30 individuals assayed, 11 belonged to the CC genotype and 19 to the TT genotype.

The pseudo MRM quantified urinary uromodulin in the 30 clinical urine samples in the range of 21 to $1344 \mathrm{nM}$, compared with a range of 39 to $699 \mathrm{nM}$ obtained with the ELISA. Generally both this ELISA assay and the pseudo MRM quantified urinary uromodulin concentrations in the sample cohort similarly $\left(r^{2}=0.7038\right.$, slope $\left.=0.471\right)$, however the pseudo MRM quantified three samples at much greater values than the ELISA (Figure 5B).

To investigate the reproducibility of urinary uromodulin quantification using the pseudo MRM method, 13 samples that covered the concentration range of urinary uromodulin from the initial assay were re-analyzed. Excellent reproducibility of the pseudo MRM assay was observed $\left(r^{2}=0.9951\right.$, slope $\left.=0.9903\right)$ (Figure 5C), providing further confidence in the reliability of the method. Using a similar approach, the 30 samples were re-analyzed using the ELISA (Figure 5D). Reduced correlation between the initial and repeated ELISA assays was observed when compared with the pseudo MRM method $\left(r^{2}=0.5895\right.$, slope $\left.=0.8332\right)$. The reduced correlation between the two ELISA measurements was expected, considering the known effects of storage duration (up to 2 years) and freezingthawing cycles on the determination of uromodulin by this method [10]. In contrast, the excellent correlation between the two pseudo MRM analyses however does suggest that this method is devoid of these sample stability and freeze-thaw issues affecting the ELISA.

Effect of the UMOD genotype on urinary levels of uromodulin

Subsequently the effect of the rs4293393 genotype on urinary uromodulin concentration was confirmed using the pseudo MRM assay (Figure 5E). In the analysis of these 30 samples, both ELISA and pseudo
MRM assays identified a significant increase in the urinary levels of uromodulin in subjects harboring the TT or CC genotype ( $p=0.001$ for pseudo MRM; $p$ $=0.0142$ for ELISA). The effect of the genotype was slightly greater for the pseudo MRM assay than ELISA (2.02-fold compared with 1.59-fold, respectively).

\section{Quantification of urinary uromodulin}

concentration in autosomal dominant tubulointerstitial kidney disease-uromodulin patients

ADTK-UMOD is considered to represent one of the clinical situations where urinary uromodulin concentration is extremely low after disease onset. Consequently we set out to test our assay and investigate whether the pseudo MRM was able to identify, and even quantify urinary uromodulin concentration in these patients. Urine was collected from four patients confirmed by genotyping to suffer from ADTKD$U M O D$ and assessed for uromodulin concentration using the $100 \mu \mathrm{l}$ pseudo MRM assay and ELISA.

Urinary uromodulin concentration was only sufficient in patient 4 to allow quantification by both surrogate peptides. For the remaining samples, urinary uromodulin concentration was below the $10 \mathrm{nM}$ LLOQ of the DWVSVVTPAR surrogate peptide. Relying solely on the STEYGEGYACDTDLR surrogate peptide urinary uromodulin concentration could be quantified in patients 2 and 3. While DWVSVVTPAR could not be quantified in these samples, the endogenous peptide could be identified through detection of the full fragmentation spectra (data not shown). While uromodulin concentration could not be quantified in urine collected from patient 1 , fragment ion spectra attributable to the endogenous STEYGEGYACDTDLR but not DWVSVVTPAR peptide could be identified (data not shown). While this sample set is too small for correlation analysis, it appears that both the pseudo MRM

Table 5. Quantification of urinary uromodulin concentration in autosomal dominant

tubulointerstitial kidney disease-uromodulin patients by pseudo multiple reaction monitoring or ELISA assay.

\begin{tabular}{|c|c|c|c|}
\hline Patient ID & $\begin{array}{l}\text { Uromodulin } \\
\text { polymorphism }\end{array}$ & Pseudo MRM (nM) & ELISA (nM) \\
\hline 1 & C126R & $\mathrm{NQ}$ & 1.16 \\
\hline 2 & C77Y & $7.75^{\dagger}$ & 3.24 \\
\hline 3 & C77Y & $2.16^{+}$ & 1.12 \\
\hline 4 & C77Y & $25.21^{\ddagger}$ & 19.54 \\
\hline \multicolumn{4}{|c|}{$\begin{array}{l}\text { NQ represents a sample where urinary uromodulin concentration was below the LLOQ for both peptides, but the STEYGEGYACDTDLR } \\
\text { peptide could be detected through identification of the precursor ion and capture of the appropriate fragment ion scan. } \\
\text { }{ }^{+} \text {Represents a sample where the urinary uromodulin concentration was below the LLOQ of the DWVSVVTPAR peptide, and therefore the } \\
\text { protein was quantified only using the STEYGEGYACDTDLR peptide. } \\
{ }^{\ddagger} \text { Represent a sample where both STEYGEGYACDTDLR and DWVSVVTPAR peptides could be used to quantify urinary uromodulin } \\
\text { concentration. }\end{array}$} \\
\hline
\end{tabular}


methods and ELISA quantified uromodulin in these samples similarly (Table 5).

\section{Conclusion}

Protein quantification by MRM critically hinges on the selection of suitable surrogate peptides. It is also widely recommended that multiple surrogate peptides should be selected for the quantification of a single protein $[34,35]$. This approach allows rapid identification of peptide specific issues affecting protein quantification. This is achieved through comparing the protein's quantification between these individual surrogate peptides. We selected an approach whereby we searched for surrogate uromodulin peptides in trypsindigested human urine. This experiment identified 16 tryptic peptides for uromodulin, accounting for $25 \%$ of the protein's sequence. The reasons for this low sequence coverage are unclear. Data-dependent analysis of a trypsin-digested commercial preparation of human uromodulin allowed only moderately increased sequence coverage to $34 \%$ (data not shown), suggesting matrix effects of urine are not primarily responsible for this low sequence coverage. The protein's N-glycosylation is also not likely to be an important factor as peptide- $N$-glycosidase F (PNGaseF) mediated deglycosylation of a uromodulin standard purified from human urine only moderately increased sequence coverage to $43 \%$ [36]. This low sequence coverage severely restricted the availability of peptides that could be investigated for their suitability to act as surrogates. However, we were able to select two surrogate peptides STEYGEGYACDTDLR and DWVSVVTPAR, for the quantification of urinary uromodulin concentration, based on the fact that they were always observable in digests of human urine. As both of these peptides quantified human urinary uromodulin concentration similarly, in this setting selection of only these two surrogate peptides for quantification is sufficient.

This approach toward selection of surrogate peptides varied from that proposed by $\mathrm{Fu} e t a l$. for the quantification of urinary uromodulin [27]. Fu et al. used in silico peptide digestion, with subsequent selection of candidate peptides for detailed testing and validation. This was necessary because different instruments for data-dependent and MRM (Orbitrap and triple-quandrupole) analyses were used that did not allow direct transfer of usable fragmentation spectra from one instrument to the other [27]. However, in our approach, the LTQ-Orbitrap mass-spectrometer is used for both data-dependent and pseudo-MRM analysis, which allows us to exactly predict the fragmentation behavior of peptides in the pseudo MRM mode. In peptide selection, Fu et al. proposed to remove peptides containing cysteine residues from consideration as surrogates due to concerns over in vitro and in vivo modification. Due to the high cysteine content of uromodulin, we feared that excluding cysteine residues from consideration could cost a large proportion of the potential surrogate peptides of the protein. These fears were exacerbated by the low-sequence coverage of both uromodulin protein standard in buffer and uromodulin in urine. In our experience however, the selected STEYGEGYACDTDLR peptide proved to represent the most optimal surrogate peptide in our studies as it was identified in all data-dependent analyses of both urine and uromodulin standard. The peptide also behaved reproducibly, and consistently provided an excellent area under the curve signal and peak shape. Conversely, we excluded peptides containing asparagine and glutamine residues from analysis over concerns that the residue could undergo unpredictable deamination [31], resulting in the potential introduction of bias into the method. However, data by Fu et al., showing the satisfactory use of both FVGQGGAR and YFIIQDR as surrogate peptides for urinary uromodulin analysis suggests that this concern may also be overly cautious. In summary, both approaches allowed the selection of suitable peptides for the quantification of uromodulin in human urine.

The appropriate selection and use of standards is an important consideration in protein quantification by MRM. We selected an approach where synthetic SIL peptide standards of the two uromodulin surrogate peptides were spiked at a known concentration into urine samples following sample digestion, immediately before desalting [37]. In the analysis of urinary uromodulin concentration in clinical samples, this approach allows normalization for varying peptide recoveries following the desalting procedure. However, as these same SIL peptides were used in constructing calibration curve and QC samples, it is notable that exogenous standards were not used in calibration curve and QC samples to account for these varying peptide recoveries. The absence of such a standard did not drastically affect the validation of the $10 \mu \mathrm{l}$ assay, although it could suggest that our estimation of the LLOQ of $250 \mathrm{nM}$ may be conservative. This hypothesis is supported by the good correlation between the analysis of the same samples using STEYGEGYACDTDLR in the 10 or $100 \mu \mathrm{l}$ assay (Supplementary Figure 2). Notably, this correlation was reduced for the DWVSVVTPAR peptide. The lack of a further exogenous standard however hindered validation of the $100 \mu \mathrm{l}$ assay. We suspect that this is a consequence of the introduction of error into the assay, as matrix effects meant that samples had to be evaporated to incomplete dryness before reconstitution to a universal volume. Precision and accuracy of the assay could be restored through the normalization of exogenous SIL-peptides in QC and 
calibration samples to their endogenous counterparts. This approach is a far from perfect solution, but it indicates the importance of spiking in a further exogenous peptide into calibration and QC samples used in both the 10 and $100 \mu$ assays. While this exogenous peptide standard need not be a differently labeled SIL-version of the surrogate peptides, its similar extraction and mass-spectrometric signal to the surrogate peptides should be experimentally verified.

The study by $\mathrm{Fu}$ et al. described an intricate approach for generation of a standard curve through spiking increasing concentrations of uromodulin standard into buffer alongside a constant concentration of SIL peptide standards. It is expected that the ratios of SIL peptide to endogenous would remain constant in both urine and in buffer, therefore allowing accurate quantification. However, they also define the LLOQ as the lowest point on the calibration curve, where recovery is $100 \pm 20 \%$ and $\mathrm{CV}$ is $<20 \%$. This value was defined as between 7.65 and $21.4 \mathrm{nM}$ urinary uromodulin concentration depending on the MRM transition [27]. We, however, have proven the increased sensitivity of our $100 \mu \mathrm{l}$ assay with an LLOQ of $1 \mathrm{nM}$ for the STEYGEGYACDTDLR peptide and $10 \mathrm{nM}$ for the DWVSVVTPAR peptide. Furthermore, as the calibration curve generated by $\mathrm{Fu}$ et al. is not generated in urine, the substantial matrix effects observed through our experiments would not be accounted for in defining the LLOQ of their assay. Consequently the LLOQ reported by Fu et al. is likely to be ambitious.

It is also notable that in the strategy that was used in our study, no normalization was used to account for protein reduction, alkylation and proteolytic enzyme digestion. These processes have been estimated to represent the greatest source of error in quantitative proteomics [38]. An ideal alternative mechanism toward the use of standards would be a human uromodulin protein standard, completely labeled with, for example, ${ }^{13} \mathrm{C}$ spiked into urine. However, these protein standards are expensive, and are not universally available. Selevsek et al. reported another approach describing the successful utilization of three commercially available yeast proteins for normalization in targeted urine proteomic investigation [17]. Failing this, selecting SIL peptides of the surrogates, but adding amino acids flanking the trypsin digestion sites has been suggested as an approach allowing some normalization for digestion enzyme efficiency. However, these peptides do not take into account factors including obstruction of the digestion enzyme from access to the digestion site by steric hindrance in intact proteins, or by incomplete reduction and alkylation, or alternatively if portions of the molecule may be aggregated as could be observed with uromodulin.
A further concern in targeted quantification of proteins is the specificity of MRM transitions [39]. The extensive sample complexity in proteomic workflows can introduce interfering signals not attributable to the analyte of interest [34]. Utilizing this pseudo MRM approach with high-resolution mass-spectrometers (HRM), including the Orbitrap-LTQ, a selected precursor ion is isolated and subsequently fragmented in the collision cell, with the mass of all resulting fragments analyzed. This allows the full fragmentation MS/MS of the peptide of interest to be captured and throughout all analyses complete specificity of the transition can be verified and assured.

Further investigations were undertaken to identify matrix effects of urine on the signal of the SIL peptides in the $100 \mu \mathrm{l}$ assay. Drying samples to completeness after desalting greatly interfered with the assay, making a linear calibration curve unachievable. We suspect that this may be attributed to urobilin, as a yellowbrown pigment deriving from urine was found to be retained on the cartridge upon desalting until elution. Upon evaporating samples to dryness, this moiety could not be resolubilized, and may have prevented solubilization of the surrogate peptides. However, further experimentation is required to define whether this yellow pigmented moiety is directly responsible for this matrix effect. This interaction was resolved by not evaporating samples to dryness after desalting, and subsequently restoring samples to a universal volume.

Despite resolving the issue with peptide resolubilization, matrix effects in urine remained substantial in the $100 \mu \mathrm{l}$ assay. SIL-STEYGEGYACDTDLR spiked into urine gave an approximate 10 -fold reduced signal when compared with when it was spiked into $50 \mathrm{mM}$ Tris buffer $\mathrm{pH}$ 8, or endogenous STEYGEGYACDTDLR released from the digestion of a commercial uromodulin standard in the same buffer. This matrix suppression is expected to drastically reduce the sensitivity of the assay. While a major focus of this assay was to provide the most simple method as possible, and with the high urinary uromodulin concentration in man meaning increased assay sensitivity was not required, a protein precipitation and acetone clean-up procedure has been described allowing quantitation of proteins in urine down to $\mathrm{pg} / \mathrm{ml}$ concentrations [17]. Alternatively a fractionation procedure has also resulted in urinary protein quantification to an LLOQ of 10 pg per $100 \mu \mathrm{g}$ total urinary protein content [16].

While it was not an intention of this work to provide a high-throughput mass-spectrometric assay, the long chromatographic gradient of $152 \mathrm{~min}$ does result in poor sample throughput, especially when compared with the ELISA. Steepening the chromatographic gradient and increasing the flow rate would reduce run- 
times. However, with the consequential shortening of peak widths through the use of very steep gradients and high flow rates, it must be ensured that sufficient data points are captured on the peaks to allow accurate analysis. Such analyses have however been reported using high-resolution mass spectrometers [40].

While in this study, a good correlation between the pseudo MRM and ELISA was observed for the quantification of uromodulin in healthy volunteers, much improved correlations between mass-spectrometric and ELISA assays have previously been reported for other proteins in serum [41], and even in urine [42], albeit when fractionation was used. The pseudo MRM method however, quantified urinary uromodulin concentration in samples up to a maximum of $1.3 \mu \mathrm{M}$ concentration, in contrast to the ELISA which quantified uromodulin in the same samples up to a maximum of 699 nM. Similarly, the method described by Fu et al. also reported the mass-spectrometric assay to quantify uromodulin at greater concentrations than the ELISA [27]. It is possible that the $\mathrm{pH}$ and ionic strength of the urine sample may have influenced the aggregation and precipitation of the protein in the ELISA, as uromodulin has been shown to precipitate under these conditions [3,43]. Commercial ELISA assays for the measurement of uromodulin include steps to normalize sample $\mathrm{pH}$ to $\mathrm{pH} 8.0$ to inhibit aggregation. This approach was also used in the pseudo MRM assay, primarily as this is the optimal $\mathrm{pH}$ for trypsin efficiency. It should be noted however, that no change in the ELISA measurement of urinary uromodulin concentration could be detected when samples were diluted in Tris-acetate buffer $\mathrm{pH} 8.0$ [10].

Despite these differences in urinary uromodulin quantification by the two methods, a statistically significant, approximate twofold increase in urinary uromodulin concentration was observed between individuals harboring the CC and TT alleles of the rs 4293393 promoter variant. This is in accordance with previously reported studies [19,21]. This result further substantiates the biological relevance of the variant, and its potential influence on the high allelic frequency of the TT genotype.

Uromodulin is currently receiving increased interest as a potential biomarker of renal damage and tubular function. In these indices, urinary uromodulin concentration is reduced when compared with healthy individuals $[8,23,44]$. Furthermore, in certain advanced nephrological conditions, urinary uromodulin concentrations can be reduced to extremely low levels [23]. Consequently, we sought to investigate whether our assay was able to identify and quantify urinary uromodulin at these low concentrations. One clinical situation where extremely low urinary uromodulin concentra- tions are consistently observed is in ADTKD-UMOD patients [23-26]. The pseudo MRM assay was able to quantify uromodulin in three out of the four patients assayed, although quantification relied on the use of only one surrogate peptide for the analysis of two of these patients. This indicates that the dynamic range of the pseudo MRM assay for STEYGEGYACDTDLR is able to span almost the entire range of clinical urinary uromodulin concentrations. While the pseudo MRM was unable to quantify urinary uromodulin in one patient, the endogenous STEYGEGYACDTDLR peptide could still be identified. The ELISA could quantify uromodulin in this sample indicating that it may still be of use in quantifying urinary uromodulin concentrations falling out of range of the pseudo MRM assay. However, resolving the matrix effects of urine which were found to cause an approximate tenfold loss in signal for both surrogate peptides may allow sufficient increases in assay sensitivity to allow quantification of urinary uromodulin in this patient and both peptides to be used in the quantification of the other three. This investigation will constitute the next focus of our work.

In this study, we have reported a sensitive, accurate and precise measurement for the quantification of uromodulin in human urine. With the availability of the full fragment spectrum of the surrogate peptides using the pseudo MRM, complete confidence in the specificity of the assay is assured. A further major advantage of the pseudo MRM assay over the ELISA is that it has the potential to allow the targeted analysis of multiple analytes in a single run. This is of particular interest in biomarker assessment, where panels of biomarkers are now often desired, potentially allowing the diagnostician further understanding into the site and mechanism of tissue injury, as well as providing information into subsequent repair.

\section{Future perspective}

Each mass-spectrometric method for the quantification of proteins by MRM critically depends on the selection of appropriate candidate surrogate peptides. However, the strategies used for the selection of such peptides remain controversial. Traditional MRM assays are typically performed on triple-quad mass-spectrometers. The scan information to combine a precursor ion with specific fragment ions is obtained from mass-spectrometric analyses run in data-dependent mode. However, the transferal of these peptides from one mass-spectrometer to another is not straightforward. Alternatively, in silico predictions can be used but extensive subsequent validation of such peptides is required as again the behavior of the peptides on the mass-spectrometer is not assured. A major advantage of the pseudo MRM described here is that both data-dependent and quantitative analyses are 
performed on the same instrument meaning these issues can be circumvented. A further advantage of the pseudo MRM method is that capture of the full fragmentation spectra of surrogate peptides allows complete confidence in the specificity of the assay. Furthermore, the extensive validation of the accuracy and precision of this method through following the FDA guidelines for bioanalytical method validation is also an approach not commonly used in quantitative proteomics; however, there is an increasing drive in the field for this validation to be taken up. In summary, the strategies used in developing this pseudo MRM may provide a useful template for the development of other quantitative proteomic assays in the future.

This accurate and reproducible method for the quantification of urinary uromodulin also exhibits potential utility in the clinical diagnosis of renal function and injury. The most obvious example where this method could show clinical application is as an initial strategy to diagnose ADTKD-UMOD, prior to confirmation by genetic testing. In this situation, urinary concentration of uromodulin is greatly reduced when compared with the rest of the population. The protein is also receiving increasing interest as a marker of CKD and renal function. Furthermore, the specific expression of the protein in the thick-ascending limb of the loop of Henle may suggest that it could be a specific marker of damage at this site. Recent studies associating urinary uromodulin concentration with markers of tubular function add further weight to this hypothesis. The pseudo MRM method described in this manuscript may represent an important tool in the further investigation of uromodulin as a biomarker of renal injury. If these studies are successful, the method may then be incorporated into clinical diagnosis regimens. This will be facilitated by the simple transferal of the pseudo MRM method to much less expensive triple-quadrupole mass spectrometers. These instruments can be used by people without extensive training, and will be represent great value in future clinical diagnostic regimens.

\section{Supplementary data}

To view the supplementary data that accompany this paper please visit the journal website at: www.future-science.com/ doi/full/10.4155/bio-2016-0055

\section{Financial \& competing interests disclosure}

TG Hammond was supported by the European Union's Seventh Framework Programme for research, technological development and demonstration under grant agreement number 608847 and the Swiss National Centre of Competence in Research (NCCR) Kidney Control of Homeostasis. A Odermatt was supported by the Novartis Research Foundation. Work in the laboratory of O Devuyst was supported by the European Community's Seventh Framework Programme (FP7/2007-2013) under grant agreement no 305608 (EURenOmics), the GebertRüef Foundation and the Swiss National Science Foundation project grant 310030_146490 and NCCR Kidney.CH Program. The authors have no other relevant affiliations or financial involvement with any organization or entity with a financial interest in or financial conflict with the subject matter or materials discussed in the manuscript apart from those disclosed.

No writing assistance was utilized in the production of this manuscript.

\section{Ethical conduct of research}

The authors state that they have obtained appropriate institutional review board approval or have followed the principles

Executive summary

\section{Background}

- Uromodulin is almost universally quantified by ELISA, despite knowledge of the protein's extensive glycosylation and aggregation which could affect its accurate measurement by this method.

- We have developed a pseudo MRM method for the absolute quantification of the protein in urine and compared quantification of urinary uromodulin in a human cohort with an established ELISA.

\section{Results \& conclusion}

- Pseudo MRM can be used to perform protein quantification and surrogate peptide selection on the same mass spectrometer.

- Due to the capture of the full fragmentation scan the pseudo MRM allows complete specificity of the assay

- Selection of just two surrogate peptides allowed the accurate and reproducible quantification by the pseudo MRM method.

- Matrix effects of urine, leading to extensive loss of signal, were observed. Due to the high abundance of uromodulin in urine this did not affect the protein's measurement, however further sample clean-up may be required for the quantification of less-abundant urinary proteins.

- The pseudo MRM method does not appear susceptible to stability and freeze-thaw issues affecting the ELISA.

Summary

- The pseudo MRM method described in this manuscript allows the accurate and reliable quantification of uromodulin in human urine and may be of value in future investigations into both the biological function of the protein and its potential utility as a biomarker of renal injury and function. 
outlined in the Declaration of Helsinki for all human or animal experimental investigations. In addition, for investigations involving human subjects, informed consent has been obtained from the participants involved.

\section{References}

Papers of special note have been highlighted as:

- of interest; $\bullet$ • of considerable interest

1 Rampoldi L, Scolari F, Amoroso A, Ghiggeri G, Devuyst O. The rediscovery of uromodulin (Tamm-Horsfall protein): from tubulointerstitial nephropathy to chronic kidney disease. Kidney Int. 80(4), 338-347 (2011).

- This comprehensive review provides a useful insight into the current thinking of the potential biological roles of uromodulin as well as the contribution of the protein to renal disease.

2 Serafini-Cessi F, Malagolini N, Cavallone D. Tamm-Horsfall glycoprotein: biology and clinical relevance. Am. J. Kidney Dis. 42(4), 658-676 (2003).

3 Tamm I, Horsfall FL Jr. Characterization and separation of an inhibitor of viral hemagglutination present in urine. Proc. Soc. Exp. Biol. Med. 74(1), 106-108 (1950).

4 Bachmann S, Mutig K, Bates J et al. Renal effects of TammHorsfall protein (uromodulin) deficiency in mice. Am. J. Physiol. 288(3), F559-F567 (2005).

5 Renigunta A, Renigunta V, Saritas T, Decher N, Mutig K, Waldegger $\mathrm{S}$. Tamm-Horsfall glycoprotein interacts with renal outer medullary potassium channel ROMK2 and regulates its function. J. Biol. Chem. 286(3), 2224-2235 (2011).

6 Bates JM, Raffi HM, Prasadan K et al. Tamm-Horsfall protein knockout mice are more prone to urinary tract infection. Kidney Int. 65(3), 791-797 (2004).

7 Eckardt KU, Alper SL, Antignac C et al. Autosomal dominant tubulointerstitial kidney disease: diagnosis, classification, and management - a KDIGO consensus report. Kidney Int. 88(4), 676-683 (2015).

8 Pruijm M, Ponte B, Ackermann D et al. Associations of urinary uromodulin with clinical characteristics and markers of tubular function in the general population. Clin. J. Am. Soc. Nephrol. 11(1), 70-80 (2016).

- In a clinical cohort of patients, urinary concentration of uromodulin was shown to correlate with established markers of renal tubular function and kidney dimensions.

9 Troyanov S, Delmas-Frenette C, Bollee G et al. Clinical, genetic, and urinary factors associated with uromodulin excretion. Clin. J. Am. Soc. Nephrol. 11(1), 62-69 (2016).

10 Youhanna S, Weber J, Beaujean V, Glaudemans B, Sobek J, Devuyst O. Determination of uromodulin in human urine: influence of storage and processing. Nephrol. Dial. Transplant. 29(1), 136-145 (2014).

11 Jovine L, Qi HY, Williams Z, Litscher E, Wassarman PM. The ZP domain is a conserved module for polymerization of extracellular proteins. Nat. Cell Biol. 4(6), 457-461 (2002).

12 Van Rooijen JJ, Voskamp AF, Kamerling JP, Vliegenthart JF. Glycosylation sites and site-specific glycosylation in human

\section{Open access}

This work is licensed under the Attribution-NonCommercial-No Derivatives 4.0 Unported License. To view a copy of this license, visit http://creativecommons.org/licenses/by-nc-nd/4.0/

Tamm-Horsfall glycoprotein. Glycobiology 9(1), 21-30 (1999).

13 Easton RL, Patankar MS, Clark GF, Morris HR, Dell A. Pregnancy-associated changes in the glycosylation of TammHorsfall glycoprotein. Expression of sialyl Lewis(x) sequences on core 2 type $\mathrm{O}$-glycans derived from uromodulin. J. Biol. Chem. 275(29), 21928-21938 (2000).

14 Thongboonkerd V. Practical points in urinary proteomics. J. Proteome Res. 6(10), 3881-3890 (2007).

15 Chen YT, Chen HW, Domanski D et al. Multiplexed quantification of 63 proteins in human urine by multiple reaction monitoring-based mass spectrometry for discovery of potential bladder cancer biomarkers. J. Proteomics 75(12), 3529-3545 (2012).

16 Shi T, Gao Y, Quek SI et al. A highly sensitive targeted mass spectrometric assay for quantification of AGR2 protein in human urine and serum. J. Proteome Res. 13(2), 875-882 (2014).

17 Selevsek N, Matondo M, Sanchez Carbayo M, Aebersold R, Domon B. Systematic quantification of peptides/proteins in urine using selected reaction monitoring. Proteomics 11(6), 1135-1147 (2011).

18 Gudbjartsson DF, Holm H, Indridason OS et al. Association of cariants at UMOD with chronic kidney disease and kidney stones-role of age and comorbid diseases. PLoS Genet. 6(7), e1001039 (2010).

19 Trudu M, Janas S, Lanzani C et al. Common noncoding $U M O D$ gene variants induce salt-sensitive hypertension and kidney damage by increasing uromodulin expression. Nat. Med. 19(12), 1655-1660 (2013).

20 Olden M, Corre T, Hayward C et al. Common variants in UMOD associate with urinary uromodulin levels: a metaanalysis. J. Am. Soc. Nephrol. 25(8), 1869-1882 (2014).

21 Kottgen A, Hwang SJ, Larson MG et al. Uromodulin levels associate with a common UMOD variant and risk for incident CKD. J. Am. Soc. Nephrol. 21(2), 337-344 (2010).

22 Eckardt KU, Alper SL, Antignac C et al. Autosomal dominant tubulointerstitial kidney disease: diagnosis, classification, and management - a KDIGO consensus report. Kidney Int. 88(4), 676-683 (2015).

- Provides the first description for a mass-spectrometric method for the quantification of human uromodulin in urine. The strategy used in the development and validation of this method vary greatly to the one described in this manuscript.

23 Prajczer S, Heidenreich U, Pfaller W, Kotanko P, Lhotta K, Jennings P. Evidence for a role of uromodulin in chronic kidney disease progression. Nephrol. Dial. Transplant. 25(6), 1896-1903 (2010).

24 Dahan K, Devuyst O, Smaers M et al. A cluster of mutations in the UMOD gene causes familial juvenile hyperuricemic nephropathy with abnormal expression of uromodulin. J. Am. Soc. Nephrol. 14(11), 2883-2893 (2003). 
-. Reports the outcome of a workshop held at the National Institute of Health in the USA aimed at proposing a consensus in strategies used in the development of quantitative proteomic methods.

25 Rampoldi L, Caridi G, Santon D et al. Allelism of MCKD, FJHN and GCKD caused by impairment of uromodulin export dynamics. Hum. Mol. Genet. 12(24), 3369-3384 (2003).

-. This document produced by the US FDA provides strategies for the validation of bioanalytical methods.

26 Vylet'al P, Kublova M, Kalbacova M et al. Alterations of uromodulin biology: a common denominator of the genetically heterogeneous FJHN/MCKD syndrome. Kidney Int. 70(6), 1155-1169 (2006).

27 Fu Q, Grote E, Zhu J et al. An empirical approach to signature peptide choice for selected reaction monitoring: quantification of uromodulin in urine. Clin. Chem. 62(1), 198-207 (2015).

28 Turner JJO, Stacey JM, Harding B et al. UROMODULIN mutations cause familial juvenile hyperuricemic nephropathy. J. Clin. Endocrinol. Metab. 88(3), 1398-1401 (2003).

29 Jennings P, Aydin S, Kotanko P et al. Membrane targeting and secretion of mutant uromodulin in familial juvenile hyperuricemic nephropathy. J. Am. Soc. Nephrol. 18(1), 264-273 (2007)

30 Bosedasgupta S, Moes S, Jenoe P, Pieters J. Cytokine-induced macropinocytosis in macrophages is regulated by 14-3-3zeta through its interaction with serine-phosphorylated coronin 1 . FEBS J. 282(7), 1167-1181 (2015).

31 Robinson NE. Protein deamidation. Proc. Natl Acad. Sci. USA 99(8), 5283-5288 (2002).

32 Carr SA, Abbatiello SE, Ackermann BL et al. Targeted peptide measurements in biology and medicine: best practices for mass spectrometry-based assay development using a fit-for-purpose approach. Mol. Cell. Proteomics 13(3), 907-917 (2014).

33 Food, Administration D. FDA guidance for industry: bioanalytical method validation. Rockville, MD: US Department of Health and Human Services. 124-129 (2001). www.fda.gov/downloads/Drugs/Guidance/ucm070107.pdf

34 Kitteringham NR, Jenkins RE, Lane CS, Elliott VL, Park BK. Multiple reaction monitoring for quantitative biomarker analysis in proteomics and metabolomics. J. Chromatogr.
B Analyt. Technol. Biomed. Life Sci. 877(13), 1229-1239 (2009).

35 Lange V, Picotti P, Domon B, Aebersold R. Selected reaction monitoring for quantitative proteomics: a tutorial. Mol. Syst. Biol. 4, 222 (2008).

36 Santambrogio S, Cattaneo A, Bernascone I et al. Urinary uromodulin carries an intact $\mathrm{ZP}$ domain generated by a conserved C-terminal proteolytic cleavage. Biochem. Biophys. Res. Commun. 370(3), 410-413 (2008).

37 Gerber SA, Rush J, Stemman O, Kirschner MW, Gygi SP. Absolute quantification of proteins and phosphoproteins from cell lysates by tandem MS. Proc. Natl Acad. Sci. USA 100 (12), 6940-6945 (2003).

38 Van Den Broek I, Romijn FP, Smit NP et al. Quantifying protein measurands by peptide measurements: where do errors arise? J. Proteome Res. 14(2), 928-942 (2015).

39 Sherman J, Mckay MJ, Ashman K, Molloy MP. How specific is my SRM?: The issue of precursor and product ion redundancy. Proteomics 9(5), 1120-1123 (2009).

40 Percy AJ, Chambers AG, Yang J, Domanski D, Borchers $\mathrm{CH}$. Comparison of standard- and nano-flow liquid chromatography platforms for MRM-based quantitation of putative plasma biomarker proteins. Anal. Bioanal. Chem. 404(4), 1089-1101 (2012).

41 Shi TJ, Fillmore TL, Sun XF et al. Antibody-free, targeted mass-spectrometric approach for quantification of proteins at low picogram per milliliter levels in human plasma/ serum. Proc. Natl Acad. Sci. USA 109(38), 15395-15400 (2012).

42 Shi TJ, Gao YQ, Quek SI et al. A highly sensitive targeted mass spectrometric assay for quantification of AGR2 protein in human urine and serum. J. Proteome Res. 13(2), 875-882 (2014).

43 Scurr DS, Robertson WG. Modifiers of calcium-oxalate crystallization found in urine.3. Studies on the role of tammhorsfall mucoprotein and of ionic-strength. J. Urol. 136(2), 505-507 (1986).

44 Zhou JJ, Chen YQ, Liu Y et al. Urinary uromodulin excretion predicts progression of chronic kidney disease resulting from IgA nephropathy. PLoS ONE 8(8), e71023 (2013). 